\title{
LoRa-IoT Focused System of Defense for Equipped Troops [LIFE]
}

\author{
${ }^{1}$ Shree Gowri Santhosh .V, ${ }^{2}$ Vishal .E, ${ }^{3}$ Vishak .R, ${ }^{4}$ Dr. K. Rahimunnisa \\ ${ }^{1}$ Student-B.E [ECE], Easwari Engineering College, Chennai, Tamil Nadu, India \\ Email: shreegowrisanthosh@gmail.com
}

${ }^{2}$ Student-B.E [ECE], Easwari Engineering College, Chennai, Tamil Nadu, India.

Email: eswaranvishal7@gmail.com

${ }^{3}$ Student-B.E [ECE], Easwari Engineering College, Chennai, Tamil Nadu, India.

Email: vishak1998ramasamy@gmail.com

${ }^{4}$ Faculty Mentor-M.E.,Ph.D., Easwari Engineering College, Chennai, Tamil Nadu, India.

Email: hod.ece20@gmail.com

\begin{abstract}
National security is the capacity of a nation to mobilize military forces to guarantee its borders and successfully defend against physical threats including military aggression and attacks by enemy troops. Every country lives peacefully as soldiers perform their duties. Furthermore, soldiers safeguard's the honor of their country. Military communication plays an important role in nation's warfare. Military communication concerns with transmission of every information from reconnaissance as well as other groups in contact with opposition. There are several issues with respect to soldiers' safety. Whenever any soldier crosses the enemy lines, it is really essential for base station to identify the position and health condition of all the soldiers. This paper presents an idea of monitoring the soldier and also testing every soldier's health condition which helps army personnel to schedule the responsive operations. This paper includes an opportunity to map the positions and record the safety of the soldiers who get lost and wounded on the front line in real time. The data from sensors and GPS module will be transmitted wirelessly utilizing the soldiers' LoRa kit. The data gathered will be uploaded to the cloud for further statistical analysis. Upon receiving the health status of soldiers, the army officials can keep track of every soldier. Our proposed system allows army personnel at bivouac to track the current GPS position of every battalion and also checks the vitals such as body temperature, blood pressure, ECG, $\mathrm{SpO} 2$ of soldiers. It also consists an extra feature with the help of that soldier can ask for help manually by pressing an alert switch to inform the army personnel at bivouac if he is in need or may have sensed the enemy intrusion.
\end{abstract}

Keywords: LoRa; Health Monitoring; Enemy Intrusion; Wireless Sensor Networks; Military Communication; Base Station

\section{Introduction}

\subsection{Wireless Sensor Networks}

Communication is the key purpose of bringing together all the items in IoT to build a network of stuff on the Internet. WC provides the benefits of simplicity, less wire, better network access and simpler Internet accessibility to any device. Additionally, WSN is one of the most popular systems used by IoT deployments. WSN has evolved over the last decade as an influential medium for linking the physical and digital environment. WSN has been used in multiple projects, such as environmental control, home tracking, smart grid, and pipeline tracking. The rewards of utilizing WSN in border monitoring are enormous. This is especially challenging to do, considering the very long land borders. WSN technology offers an intelligence-led, cost-effective approach for tracking sensitive areas at international borders. WSNs as border surveillance networks have many features that add to its effectiveness. LPWANs, due to their low cost and long-range connectivity, can improve existing and several future IoT applications.

\subsection{Military Oriented Communication}

Our paper discusses and defines mechanisms for the efficient and successful usage of military communication. Since fighting powers are always on the run, exchanging knowledge and details include a mobile network to accommodate their mobility. Wireless networks must be able to tolerate the remoteness and deprivation of military-activity zones. Communication is one of the key concerns of a combat operation. Our suggested program 
proposes the creation of a potential soldiers contact device with mobile WSN. The functional areas are considered to be restricted and challenging environments. This device sends the information collected regarding the death, real time position information, also protection monitoring and health status to base station.

Communication is one of the big challenges of a military campaign, especially, i) there is no death alert device, ii) inability to track the real time status of soldiers, iii) inability to receive the enemy intrusion information from soldiers.

\subsection{Major Perspective}

It is essential to establish reliable, safe and rapid response solutions for soldiers in dangerous environments. This paper describes a network of sensors on the Internet of Things that are built to track soldiers via a Lora wireless network.

The soldier must be fitted with advanced healthcare monitoring, real-time GPS to send data to the control unit. To do so, the soldier might need to link wireless networks to the control center. Aside from the country's defense, the soldier must be secured by protecting himself and the army control unit must also track the health condition of the soldier.

One of the basic issues of military operations is that the soldiers could not communicate with the base station. Our proposed system focuses on monitoring the soldier's position and is helpful for the base station to learn the soldier's exact location which is obtained using GPS module. Furthermore, this device should be useful to the soldiers taking part in special operations also. Health related instruments are installed on the armor of the troops, including BP sensor, ECG sensor, $\mathrm{SpO} 2$ sensor, temperature sensor. The information collected at the bivouac will be used for further analysis. It can help the military base to keep track of every soldier.

This paper is structured as per the following. Section 2 explains the objectives of our work. Section 3 explains the literature survey. Section 4 explains the background of the study and technology utilized. Section 5 addresses how the proposed model would operate with complete descriptions of its implementation. Section 6 and 7 eventually concludes the paper with a focus on the nature of the upcoming research.

\section{Targets}

The major purpose of this project was to develop and incorporate a full framework to control and map the health details and position of soldiers in a battlefield using LoRa module. Implement a device capable of collecting the vitals-blood pressure, temperature, ECG and $\mathrm{SpO} 2$ of battalion. Also, to know about the soldiers' need in emergency circumstances. To transmit the collected data over long distances with minimal power requirements. Plan and develop a cloud server for quick data access, analyzing real time data, and early and efficient rescue tracking.

\section{Review of Literary Works}

The authors [1] had experimented with the usage of solar cells and super condensers for self- environmental sensors. The wearable protection node framework allows for an atmosphere control device focused on LoRa. In this device, different hazardous environmental parameters are calculated. This machine uses module RFM95 as the critical RF module $-148 \mathrm{db}$. The module is a low-, long- transceiver package, providing strong tolerance to interruption while reducing current use. This massively saves power and improves LoRa node life. The wearable protection node program is focused on tracking just the area, but the individual operating in the dangerous setting is not being tracked. This is less effective as the machine utilizes aggressive power saving methods.

The authors [2] had examined the battery power output in the experimental IoT-LoRa system to monitor a psychologically disordered individual. Live data are submitted to hospital. It utilizes a Dragino LoRa shield that runs at $915 \mathrm{MHZ}$ band and utilizes an Arduino Uno and a WeMos Wi-Fi module to connect it. The system relies on patient monitoring. The program is solely based on patient surveillance, which does not include any vitals monitoring. The patient monitoring device is mainly used to identify patients and not their health, so it can contribute to patient injuries. And if the patient runs quicker the position is not registered by the machine. 
The authors [3] had offered an analysis of the usage of low-power large area networks and the benefits and demerits of accessible technologies such as LoRa, Sigfox, TeleNSA and NB-IoT. It provides for the potential reach of growing development. LoRa has many benefits compared with other systems. It offers strong distribution of network all over the globe, multi-country delivery, and long service life.

The authors [4][5][6] had presented various portable, light-weighted and small-scale sensors designed to monitor human physiology. The BSN comprises of numerous biomedical sensors like blood pressure sensor, an ECG sensor, an EDA sensor which can be installed on the human body for real-time monitoring of safety.

The authors [7] had introduced a program that allows monitoring the soldiers. In their paper, the soldiers could connect with the control unit using GPS coordinate details. It is capable of conveying the sensed and perceived parameters of soldiers in real time. They have used BSN to monitor the safety metrics of the soldiers such as breathing, body temperature, etc. Data are wirelessly transmitted via GSM.

The authors [8][9][10][11] had used sensors to monitor soldier's health condition as well as weapons on them to bring forth an idea of soldiers security. The GPS module was used for positioning tracking, and the RF module was used for short-data transmitting and wireless soldier-to-soldier communications [12][18].

The authors [13][17] had investigated on the care of patients who were extremely ill. This paper focuses on monitoring the remote patients' health after they are released from hospital. This system lets doctors track patient safety parameters such as body temperature, heartbeat, and ECG from their hospital itself. The safety parameters of patients are continuously calculated and transmitted wirelessly through the ZigBee [14][15][16] transceiver.

The authors [19] had recommended soldiers' position and health tracking program utilizing the barometric pressure monitors, GPS, GSM, and WBASNs (heartbeat monitors, temperature sensors). For their project they used ATmega328p Microcontroller. Easy conditional assumptions have been used without any preparation or computer learning to identify the health of soldiers. GSM was used as a way of connectivity which will not be successful in places of high altitude where network coverage would be a major challenge. A message is sent at regular intervals and includes the health condition of the soldier utilizing GSM.

The authors [20] had proposed soldier's monitoring and health indication system utilizing GPS, vibration sensor, heart rate monitor, explosive detector, temperature sensor and a microcontroller PIC16F877A. This work utilizes a pulse sensor with an RMC01 processor and polar heart rate sensing transmitter. This paper indicates the piezo disk vibration sensor could be used with piezoelectric layer. Piezoelectric film is a lightweight, portable, reliable, versatile and low cost alternative to costly sensors.

More recently, a border intrusion monitoring program had been developed to increase coverage rates and identification precision in [21]. A formula is introduced to calculate the amount of redundancy required to ensure the sensing coverage is accurate. The writers were not providing the full description of the concept and are neglecting the practical problems of deploying nodes. Furthermore, the authors' claims on decreased false alerts, determining the location of the crossover, the identification precision, were not experimentally checked.

FleGSens [22] is a common area surveillance system that only uses simple passive infrared sensors to detect trespasses. It focuses on preserving the integrity and authenticity of reported events in the presence of an intruder, theoretically damaging a limited number of nodes. The Network itself assumes a grid topology. The hop-based routing lacks load balancing and link stability which is critical in aggressive environments and can have a direct impact on packet delivery ratio and timeliness.

Real-time monitoring of the ECG was reported in the paper [23] for patients utilizing the Session Initiation Protocol and ZigBee, and other physiological signs from various patients can be identified in the paper [24] that are readily accessible by health care practitioners.

The authors [25] had discussed about a ZigBee-based ECG-control system. Their software includes a Computer with a graphical user interface. Since the Bluetooth operates on low energy, the authors [26] had developed mechanism for mobile technologies to monitor the patient's ECG signal. 


\section{TECHNOLOGY UTILIZED 4.1 Background}

IoT vows to revolutionize the way we live and function. It may help us solve the world's top problems of demographic development, oil crises, lack of capital, and pollution. To realize this vision, animals need to sense their world, communicate this awareness with each other and with humans so that rational decision-making will have a beneficial impact on our whole ecosystem. IoT is of immense importance, regardless of this promise.

Because of their capacity to create massive surveillance systems with low installation costs and good energy efficiency, Low Wide Area Networks are gaining immense popularity among the myriad supporting IoT technologies. LoRa describes the patented PHY wireless network rather LoRaWAN is open standard introduced by the LoRa Partnership and specifies operations of the MAC layer and network design. LPWA developments have been of considerable concern in recent years, gaining rapid momentum and users support in the understanding of the IoT.

LoRa can be used in high-altitude combat zones where wireless network coverage is either lacking or may not be able to provide data transmission. This paper offers an overview of tracking the army personnel as well as presenting the health condition of the soldier during the battle, and lets the military forces plan the fighting strategy.

\subsection{LoRa Overview}

LoRa is a system of physical layers that modulates the signals in the SUB-GHZ ISM band utilizing the patented distributed spectrum methodology developed and commercialized by Semtech Corporation. A unique CSS methodology offers bidirectional connectivity, which extends a small input band signal over a larger channel bandwidth. The resulting signal has noise-like properties which render detecting or jamming more difficult. The transmission benefit allows for interruption and tolerance to noise.

LoRa is a CSS derivative with integrated FEC system. Transmissions use a large band to combat disturbance and control the frequency fluctuations generated by low cost crystals. A LoRa receiver will decipher transmissions below noise level of $19.5 \mathrm{~dB}$, thereby allowing very long intervals of communication. The main features of LPWANs that will support IoT network architecture are: low cost network delivery equipment, low power usage, simple to install national network infrastructure, secure, extended coverage, strong robustness, multi-path resistance, Doppler resistance. LoRa transceivers available today can run between $137 \mathrm{MHz}$ and $1020 \mathrm{MHz}$, and can also work in approved bands as well. However they are generally used in ISM bands (EU: $868 \mathrm{MHz}$ and 433 MHz, USA: $915 \mathrm{MHz}$ and $433 \mathrm{MHz}$ ). They scatter a narrowband signal but with the same power density over a broader frequency band. LoRa utilizes Chirp Spread Spectrum. The adaptive data rate chirp modulation technology is essential to the success of LoRa, allowing for scalable long-range communication with low power consumption and low cost architecture. Multiple access spectrum modulation strategies that suit several users in one channel effectively do this.

A number of applicants caught the research world by surprise, aiming vigorously towards accelerated standardization, recognition, and commercial adoption. Some LPWA networks operate at $169,433,868 / 915 \mathrm{MHz}$ and $2.4 \mathrm{GHz}$ depending on the region in which the unlicensed ISM bands are running. Some of the most common candidates for LPWA include SigFox, LoRa, Weightless, and Ingenu.

\section{Our Suggested Strategy}

The proposed device measures soldiers' vitals-blood pressure, temperature, ECG, SpO2 and offers an interface for any abnormality messaging. Using the latest LoRa system, renowned for its long distance communication and low power consumption, which operates without any mobile or cellular networks, the tracked information is transmitted to base station. The system also provides the soldiers with a geo-location indicator. The framework using LoRa is then merged with IoT to include a web server to monitor and analyze the values. An alert switch is also issued for the soldiers so that they can use the button to transmit their geo-location to the base station in case of any emergencies even though the vitals are not irregular. 
Journal of Ubiquitous Computing and Communication Technologies (UCCT) (2020)

Vol.02/ No.03

Pages: $153-177$

https://www.irojournals.com/jucct/

DOI: https://doi.org/10.36548/jucct.2020.3.005

\subsection{Introduction of Framework}

A remote health management system is composed of three key components, namely sensing module, processing module, and communication module. The device sensing module consists of wireless body sensor networks, which senses shifts in physiological parameters. The details would then be sent to the microcontroller for the data processing module. The processing element analyzes the input signals. If the sensed values differ from the normal values, the communication module is used to transfer data between both the receiver and the transmitter. The data is transmitted along with the GPS position coordinates.

Soldier surveillance is applicable in different situations where the soldier is in the following circumstances:

- In an enemy state of aggression - e.g. where the soldier senses an enemy assault.

- In a life-threatening state - e.g. when there is an indication of abnormality in anyone of their vitals.

\subsection{Proposed Kit}

In addition to LoRa module, the Node MCU is fitted with all sensors such as Temperature sensor, BP sensor, ECG sensor, $\mathrm{SpO} 2$ sensor and GPS Module. Each and every soldier is fitted with such a platform where the real time values of various sensors along with the soldiers' location are sent to the military base through the LoRa module because it supports long- communication and even quick communication. Data analytics is applied on the accumulated data which is available on the cloud to give details regarding the soldier's unit, such as whether he is injured or dead or in any emergency situation. The real time position, along with the well-being of the soldiers who are deployed on the frontline, can be monitored from the web platform which can thus therefore allow the army personnel at bivouac to take immediate actions.

\subsection{Architecture Layout}

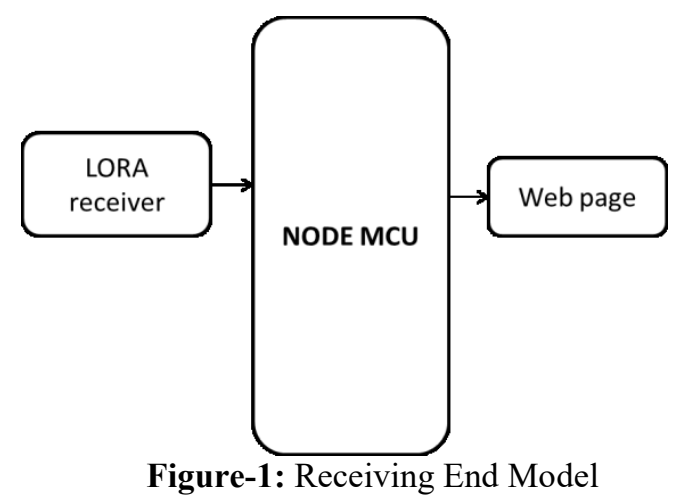

Figure-1: Receiving End Model 
Vol.02/ No.03

Pages: $153-177$

https://www.irojournals.com/jucct/

DOI: https://doi.org/10.36548/jucct.2020.3.005

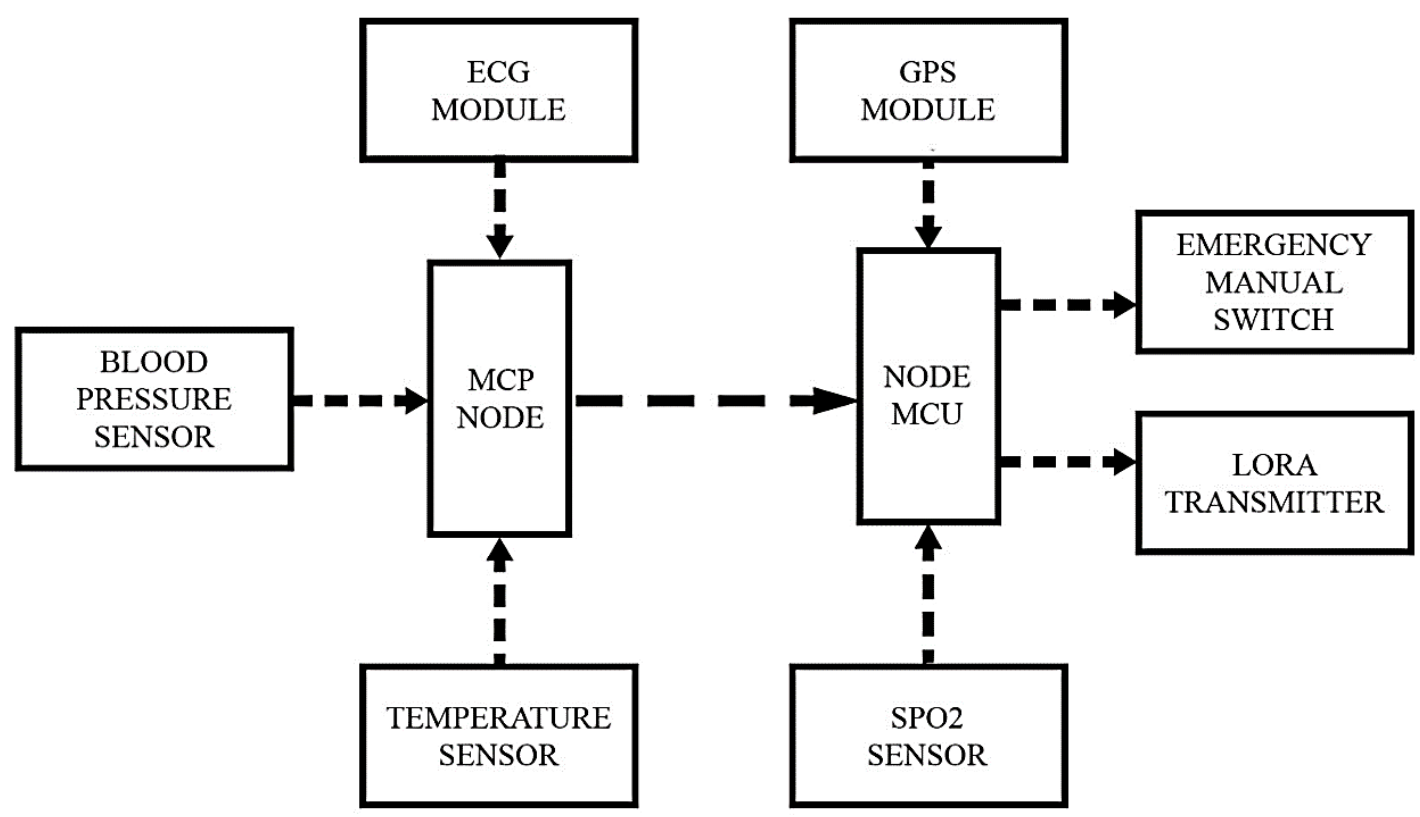

Figure-2: Transmitting End Model

Illustration - Transmitting End:

The temperature sensor (LM35), blood pressure sensor, and ECG sensor (AD8232) are all interfaced with Node MCU controller (ESP8266) directly. While the SpO2 sensor (MAX30100), and GPS module (NEO-6M) are connected to ADC (MCP3008) which is interfaced with Node MCU. All the sensors analyse the corresponding values and send them to the controller. There is also a presence of manual switch interfaced with the controller which is necessary in case of any emergency situations. The LoRa module which exists in the setup transmits the data which is obtained through the node MCU controller. The data are transmitted by the LoRa transmitter only if any abnormal readings are detected by the respective sensors or the emergency manual switch is pressed. The transmitted data by the LoRa module is received by the LoRa module which is assigned as the receiver. The transmitted data via LoRa technology is sent in the form of a string to the receiver. The software code is implemented using Arduino IDE [separate codes for transmitting and receiving arena]. In real time scenario, this model is setup at soldier's unit [combat vests or body armor].

Illustration - Receiving End:

At the receiving end, the LoRa receiver is also interfaced with node MCU (ESP8266) controller. The data [health readings analysed by various sensors along with the position measured by the GPS module] received by the LoRa receiver is provided to the controller (Node MCU) which separates the string data and updates the information in a web page which is maintained at the receiving end. Web page is utilized to visualize the data more effectively. MATLAB is used to statistically analyse the data transmitted in real time. In real time scenario, this model is setup at the central base station.

\subsection{Hardware Materials Utilized}

GPS module

BP sensor

$\mathrm{SpO} 2$ sensor

ECG sensor

Temperature sensor

LORA transmitter

LORA receiver

Node MCU

ADC

Emergency Manual Button 
Journal of Ubiquitous Computing and Communication Technologies (UCCT) (2020)

Vol.02/ No.03

Pages: $153-177$

https://www.irojournals.com/jucct/

DOI: https://doi.org/10.36548/jucct.2020.3.005

\subsection{Software Materials Utilized}

Arduino IDE

MATLAB

\subsection{Components and Specifications}

5.6.1 GPS Sensor

The GPS device (NEO-6M) is used from base station to monitor the tracking of soldier position and indicators of health status. GPS receiver is utilized to record the longitude and latitude of the military team unit, which is being stored in the microcontroller memory. It receives and tests the signal from the space-based GPS satellite to determine its geographic location.

Features

- Module with active antenna integrated and built-in EEPROM.

- $25 \times 25 \times 4 \mathrm{~mm}$ built-in ceramic active antenna which provides satellite search capability.

- Power along with signal indicator lights and a data backup battery.

- 3-5V power supply; $9600 \mathrm{bps}$ baud rate (default).

- RS232 TTL interface

\subsubsection{Temperature Sensor}

This sensor is used to track the state of health and mortality. The LM35 series are integrated circuit -temperature sensors which are accurate, whose output voltage obtained varies linearly as the temperature at Celsius (Centigrade). The low output impedance, linear output, and accurate inherent calibration of the LM35 make interfacing particularly simple to read or monitor circuitry. These can be used with single power sources, or sources with plus and minus.

Features

- Calibrated directly in ${ }^{\circ}$ Celsius (Centigrade)

- Linear $+10.0 \mathrm{mV} /{ }^{\circ} \mathrm{C}$ - scale factor

- $0.5^{\circ} \mathrm{C}$ accuracy at $+25^{\circ} \mathrm{C}$

- $-55^{\circ}$ to $+150^{\circ} \mathrm{C}$ (full rated range)

- Low cost due to wafer-level trimming

- Operates from 4 - 30 volts

- Less than $60 \mu \mathrm{A}$ current drain

- Self-heating is low, $0.08^{\circ} \mathrm{C}$ - still air

- $\pm 1 / 4^{\circ} \mathrm{C}$ typical (nonlinearity)

- Output impedance is low

\subsubsection{BP sensor}

The BP sensor is used for calculating blood pressure levels and blood pressure level control. The BP sensor is a sensor which is not invasive. This Sensor is safe to use, being non-invasive. It's easier to use and any person can control. Instead of measuring the levels of mercury and estimating pressure, this sensor makes the job simpler by automatically providing results.

Blood pressure is an essential indicator that everyone needs to have. To achieve pressure levels, this paper uses sphygmomanometer. It is an instrument used for measuring blood pressure. It consists of a rubber cuff (inflatable) that is wrapped around the arm allowing the determination of both diastolic and systolic BP by increasing the pressure and gradually releasing pressure in the cuff.

For maintaining good fitness, the ideal blood pressure level is $120 / 80 \mathrm{~mm} \mathrm{Hg}$. This reading decreases the likelihood of experiencing stroke, coronary, and renal disorders. The human being has a much lower chance of heart attack or stroke at this stage. Effects of blood supply are known as Korotkoff effects. Temperature and blood pressure measurements are taken manually, and results are transmitted by correct programming codes.

\subsubsection{ECG Sensor}

This sensor is a cost efficient board used to test the heart's electrical activity. The electrical activity is charted as an Electrocardiogram or ECG with analog output. ECGs can be very noisy. The AD8232 (Single Lead) Heart Rate Monitor functions as op-amp to quickly obtain a consistent PR and QT signal from the intervals.

Features

- $3.3 \mathrm{~V}$ - Operating voltage 
Journal of Ubiquitous Computing and Communication Technologies (UCCT) (2020)

Vol.02/ No.03

Pages: $153-177$

https://www.irojournals.com/jucct/

DOI: https://doi.org/10.36548/jucct.2020.3.005

- Output - Analog

- Detection: Leads Off

- Shutdown Pin with an LED Indicator

- $3.5 \mathrm{~mm}$ Jack - Pad Connection (biomedical)

\subsubsection{SpO2 Sensor}

Pulse Oximeter are low-cost non-invasive surgical instruments that are used to track the saturation of oxygen (SpO2) in the blood continuously. The sum of oxygen-filled blood is noted here. The MAX30100 is an optimized system device for the pulse oximetry and heartrate control. For monitor pulse oximetry and heart rate signals, it incorporates two lights, a picture detector, advanced lenses, and low noise analog signal processing. The MAX30100 can work with 3.3V and 1.8V power supplies. MAX30100 can be shut down with negligible standby current using software, enabling the power supply to remain linked at any time.

Features

$5.6 \mathrm{~mm} \times 2.8 \mathrm{~mm} \times 1.2 \mathrm{~mm}$ and 14-Pin enhanced optically SiP

Increased battery life

Low power consumption

Sample rate - programmable and power savings with LED current

Shutdown current is low $(0.7 \mu \mathrm{A})$

Fast output data

\subsubsection{Node MCU}

The board has the ESP-12E module which contains the ESP8266 chip. The chip has a Tensilica Xtensa 32-bit LX106 RISC microprocessor. The microprocessor functions at $80-160 \mathrm{MHz}$ clock frequency (adjustable) and also supports RTOS. The data collected using all sensors are processed using the Node MCU. Here we use C language for MCU node programming. Node MCU tends to take choices based on the collected sensor data. Also, it can be programmed with the AT-commands or Arduino IDE or Lua Script making it user friendly.

Features of ESP8266-01

- Compact Wi-Fi Module

- $+3.3 \mathrm{~V}$ power supply

- $100 \mathrm{~mA}$ - current consumption

- $3.6 \mathrm{~V}$ max I/O voltage

- $12 \mathrm{~mA} \max \mathrm{I} / \mathrm{O}$ source current

- 32-bit MCU built-in@ 80MHz

- Flash Memory - 512kB

- Utilized mostly as Access Point

- Supports (<10uA) Deep sleep

- Serial communication

\subsubsection{LoRa Module}

LoRa is a patented technique developed by Semtech for modulation of the spread spectrum. The LoRa module selected is LoRa SX1276/WIR-1286. The module is a low-power and long-range transceiver design, providing good resistance to disturbance thus minimizing current usage. It has a high strength of $148 \mathrm{dBm}$. The receiving current is incredibly low. The LoRa module interfaces with MCU via the SPI.

Features

Modulation: FSK, GFSK

Receiver sensitivity- supports till $-148 \mathrm{dBm}$

$22 \mathrm{~mm} \times 36 \mathrm{~mm} \times 3 \mathrm{~mm}$ (small size) form factor

Frequency Band: RF

Communication: Serial Link

Frequency Band: $868 \mathrm{MHz}$

Power: $20 \mathrm{db}$

Connectivity: RS-485, RS-232, RS-422 or 3.3V

Address Bus: 16bits network and 16bits node address

Distance coverage: $>15 \mathrm{Km}$ (sub-urban), $>5 \mathrm{Km}$ (urban)

Applications: IoT, M2M, etc. 
Journal of Ubiquitous Computing and Communication Technologies (UCCT) (2020)

Vol.02/ No.03

Pages: $153-177$

https://www.irojournals.com/jucct/

DOI: https://doi.org/10.36548/jucct.2020.3.005

Supply Voltage: $2.1 \mathrm{~V}$ to 3.6 Volts

Temperature range: -40 degree $\mathrm{C}$ to +85 degree $\mathrm{C}$

Receive current: $10.3 \mathrm{~mA}$

Sleep current: $0.2 \mu \mathrm{A}$

Transmit current: $20 \mathrm{~mA}-120 \mathrm{~mA}$

Output power: $+14 \mathrm{dBm} \max$

5.6.8 ADC

The MCP3008 is an 8-channel 10-bit ADC converter. It's inexpensive, simple to mount and doesn't require any external components. Within a compact box, it blends good efficiency and low power consumption making it suitable for embedded control applications. The MCP3008 incorporates a sequential SPI serial controller and an industry SAR design. The MCP3008 has a small power consumption (average standby of $5 \mathrm{nA}$, average active of $425 \mu \mathrm{A}$ ), and is available in PDIP and SOIC bundles of 16 pins.

Features

- 10-bit resolution

- 8 single-ended channels

- SPI interface

- 200 ksps sample rate @ 5V

- -40 to $+85^{\circ} \mathrm{C}$ : Temperature range

- Supply Current $-500 \mu \mathrm{A}(\max )$

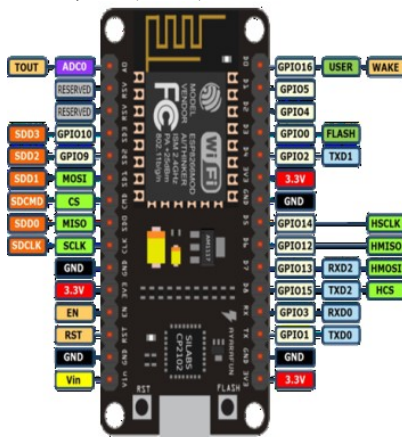

Figure-3: Node MCU

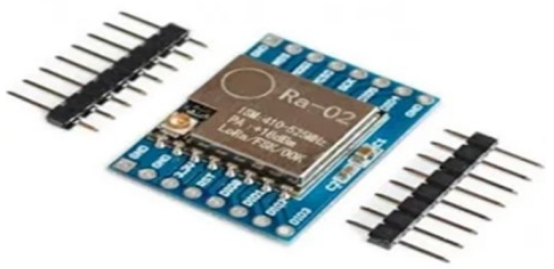

Figure-5: LoRa module

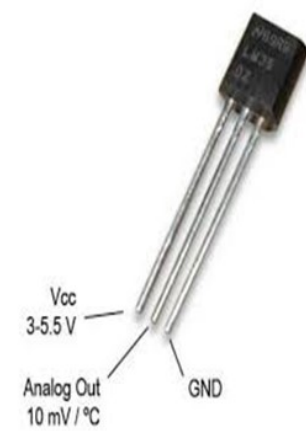

Figure-4: Temperature sensor

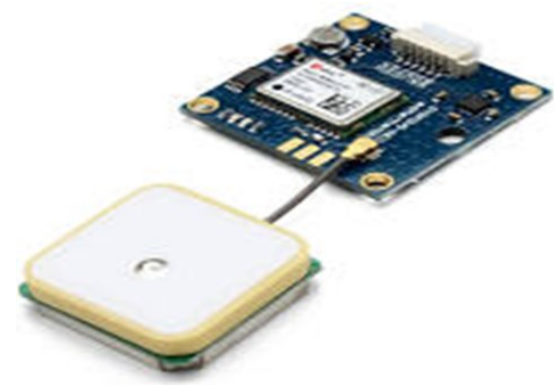

Figure-6: GPS module 
Vol.02/ No.03

Pages: $153-177$

https://www.irojournals.com/jucct/

DOI: https://doi.org/10.36548/jucct.2020.3.005

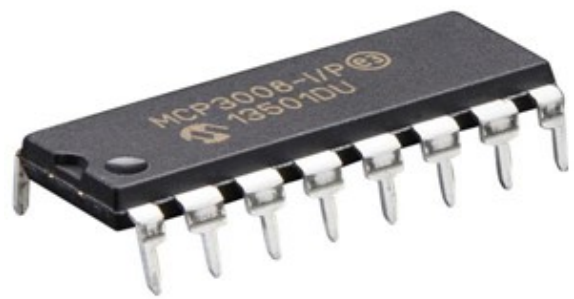

Figure-7: ADC

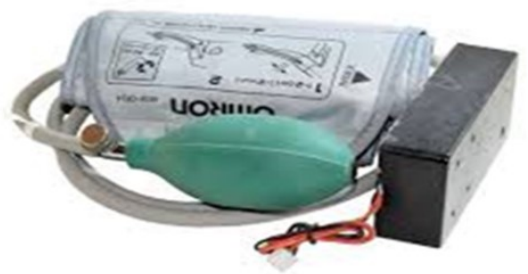

Figure-9: BP sensor

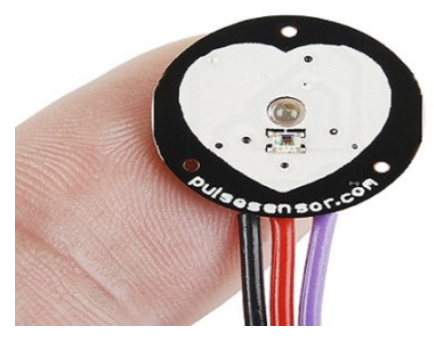

Figure-8: $\mathrm{SpO} 2$ sensor

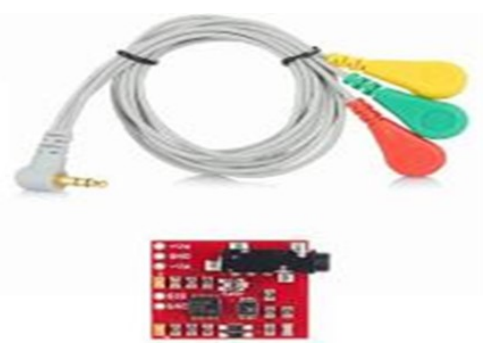

Figure-10: ECG sensor

\subsubsection{Arduino IDE}

IDE stands for 'Integrated Development Environment', an approved program developed by Arduino.cc, which is mainly used to modify, compile and upload the application to the Arduino System. Nearly all Arduino devices are compliant with this open source program and are freely available to load and continue to compile all the code. It is an open source program mainly used to compile and compose the application into the Arduino Board.

- It's an approved Arduino app, allowing application compilation so quick to get your feet wet with the learning phase even for a regular citizen has no previous technological experience.

- Operating systems such as MAC, Windows and Linux operate effortlessly on the Java Platform with built-in operations and instructions which play a key role in debugging, editing and compiling code in the environment.

- A selection of usable Arduino modules like Arduino Uno, Arduino Super, Arduino Leonardo, Arduino Micro and several others.

- Each of them includes a board microcontroller that is actually configured and recognizes the information in code format.

- Finally, the key application, also known as the sketch, generated on the IDE platform would produce a Hex File that is downloaded and submitted to the board controller.

This framework embraces both the languages $\mathrm{C}$ and $\mathrm{C}++$. 
Journal of Ubiquitous Computing and Communication Technologies (UCCT) (2020)

Vol.02/ No.03

Pages: $153-177$

https://www.irojournals.com/jucct/

DOI: https://doi.org/10.36548/jucct.2020.3.005

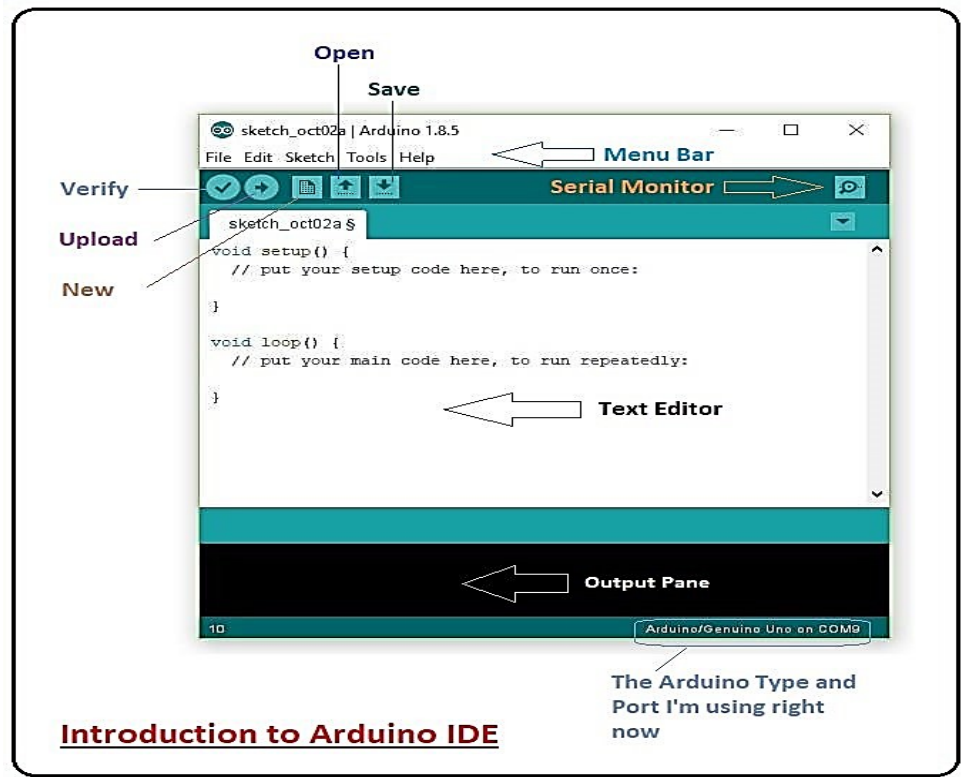

Figure-11: Arduino IDE software environment

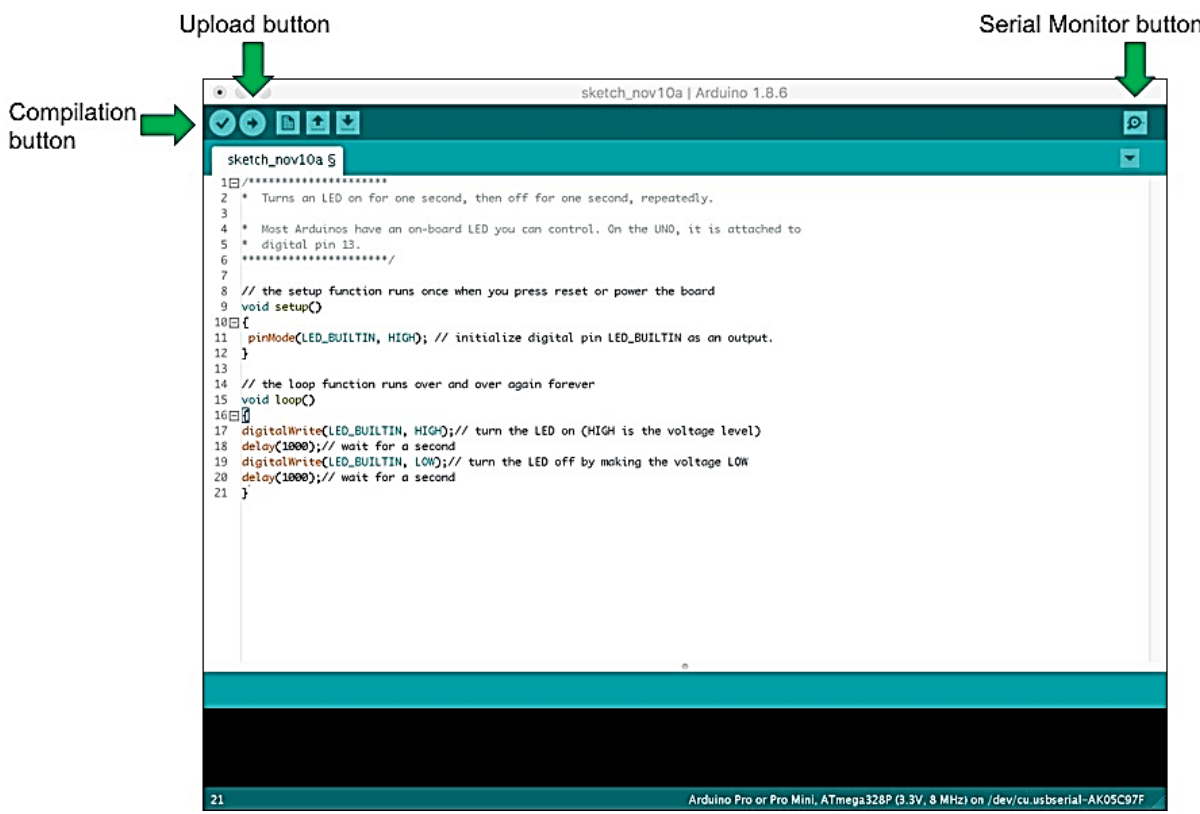

Figure-12: Arduino IDE software interface page

\subsubsection{MATLAB}

MATLAB is a high-performance technical-computing language. It combines calculation, simulation, and scripting into an easy-to-use framework where common mathematical notation communicates problems and solutions.

MATLAB is an interactive program whose fundamental data aspect is an array that needs no dimensioning. This helps you to solve several computing problems arising in a small time which is needed to write programs in noninteractive scalar language like FORTRAN or $\mathrm{C}$ especially with vector and matrix formulations.

MATLAB's term stands for laboratory with matrix. MATLAB was originally written in order to provide simple access to matrix applications built by the projects LINPACK and EISPACK. Today, MATLAB uses applications created by the projects LAPACK and ARPACK, which together reflect the state-of - the-art matrix computing tools. 
Journal of Ubiquitous Computing and Communication Technologies (UCCT) (2020)

Vol.02/ No.03

Pages: $153-177$

https://www.irojournals.com/jucct/

DOI: https://doi.org/10.36548/jucct.2020.3.005

Through feedback from multiple users MATLAB has developed over a number of years. This is the basic teaching resource in academic settings for intermediate and advanced math, electronics, and science classes. In business, MATLAB is the method of choice for study, growth, and review on high productivity.

MATLAB includes a set of toolboxes called application-specific solutions. Toolboxes, which are really relevant to most MATLAB users, help you to understand and implement specialized technologies. Toolboxes are extensive sets of MATLAB functions (M-files), which expand the MATLAB framework to solve different problem groups. Signal processing, control structures, simulation, neural networks, wavelets, fuzzy logic and several others are fields where toolboxes are available.

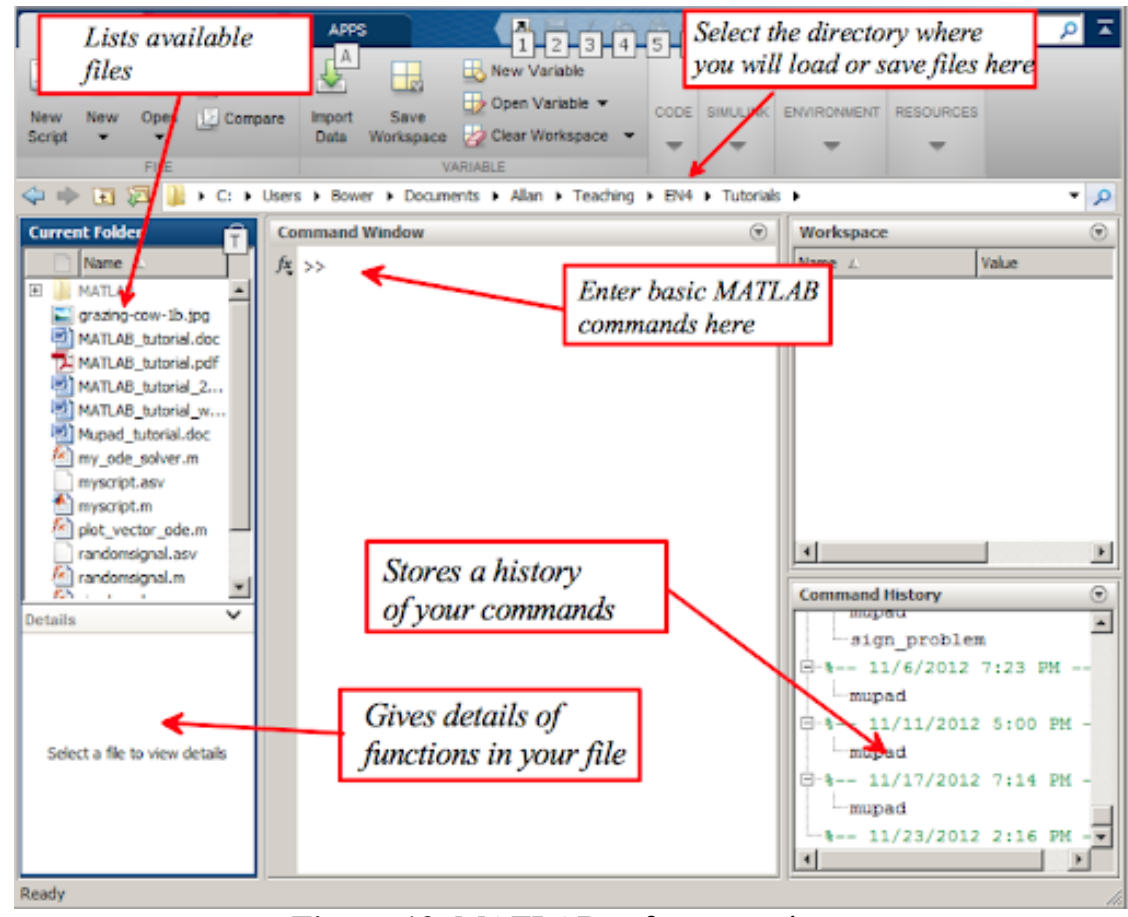

Figure-13: MATLAB software environment

\subsection{Suggested Plan}

Data which is collected from the battlefield will suggest soldiers' health status. Specific sensors are suggested for deployment and the data analyses carried out help map to the base station the conditions surrounding the soldiers. Transmission of the data from the soldiers to the bivouac is done through LoRa. Data is being transmitted when the readings of the soldier analyzed by the biomedical sensors are irregular or even when the soldier presses the emergency alert switch. Sensor values will help us describe the soldier as fine, unhealthy or dead or requires an immediate help. When the data is gathered and stored, they will be evaluated by the military base for further instinctive summaries.

\subsection{Implemented Mechanism}

The device consists of the sensors like BP Sensor, ECG Sensor, SpO2 Sensor, Temperature Sensor, GPS module in the armor. Such sensors are used to identify health parameters of soldiers, and to track their location. Using analog to digital converters, perceived analog signals are translated to digital signals and correlated with normal levels. If there is a disparity between the perceived signals and the standard normal signals, at that instant an emergency is called. The soldier shall have a LoRa module that shall be used for the communication between the base station and the soldier. The Army base station device shall consist of a Computer and LoRa transceiver module which shall be connected to each other. Collected information coming from the LoRa module may be viewed on a Desktop device using the website or GUI. 
Journal of Ubiquitous Computing and Communication Technologies (UCCT) (2020)

Vol.02/ No.03

Pages: $153-177$

https://www.irojournals.com/jucct/

DOI: https://doi.org/10.36548/jucct.2020.3.005

\subsection{Artistic Rendering}

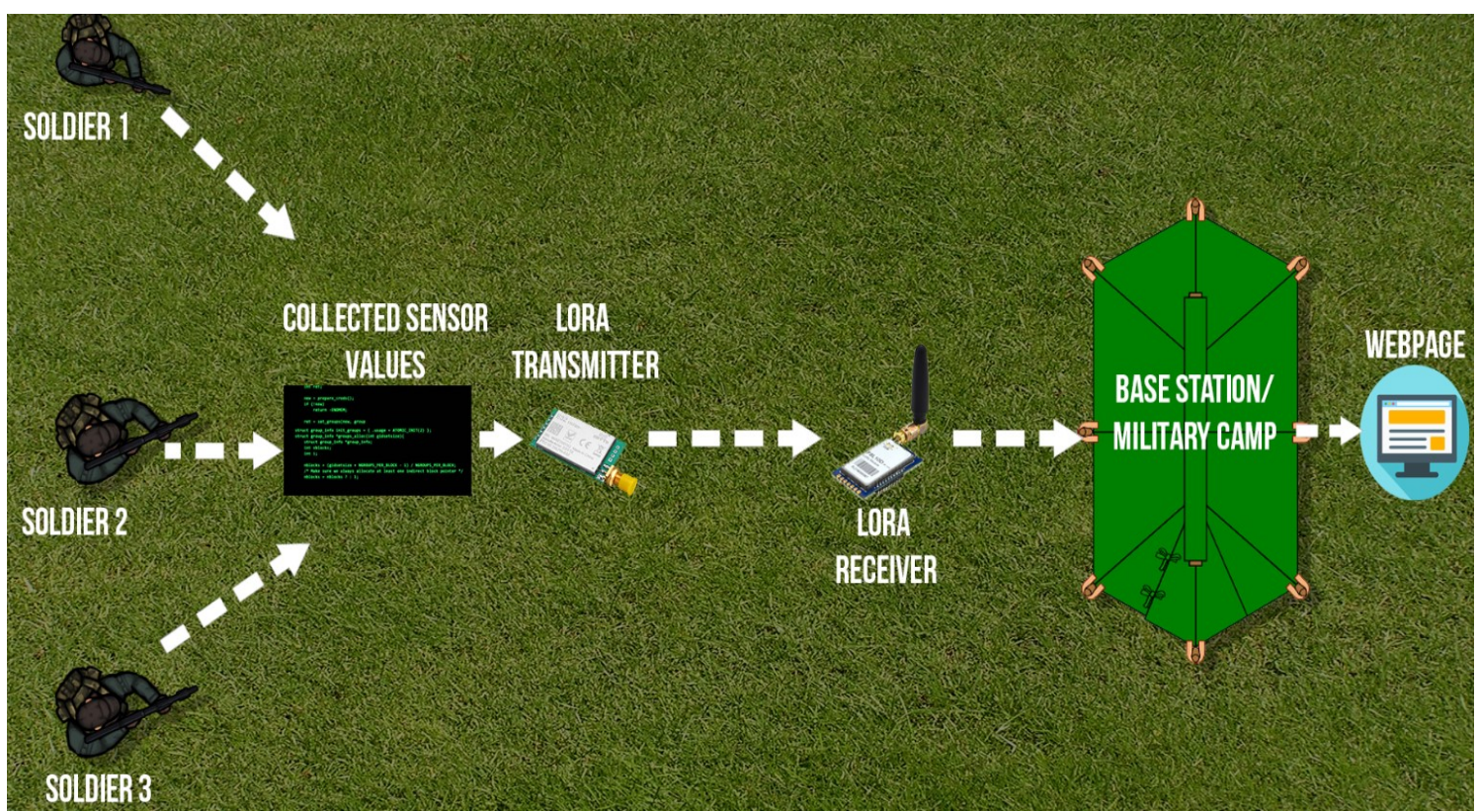

Figure-14: Pictorial Representation of Our Suggested Approach

\subsection{Workflow Representation}

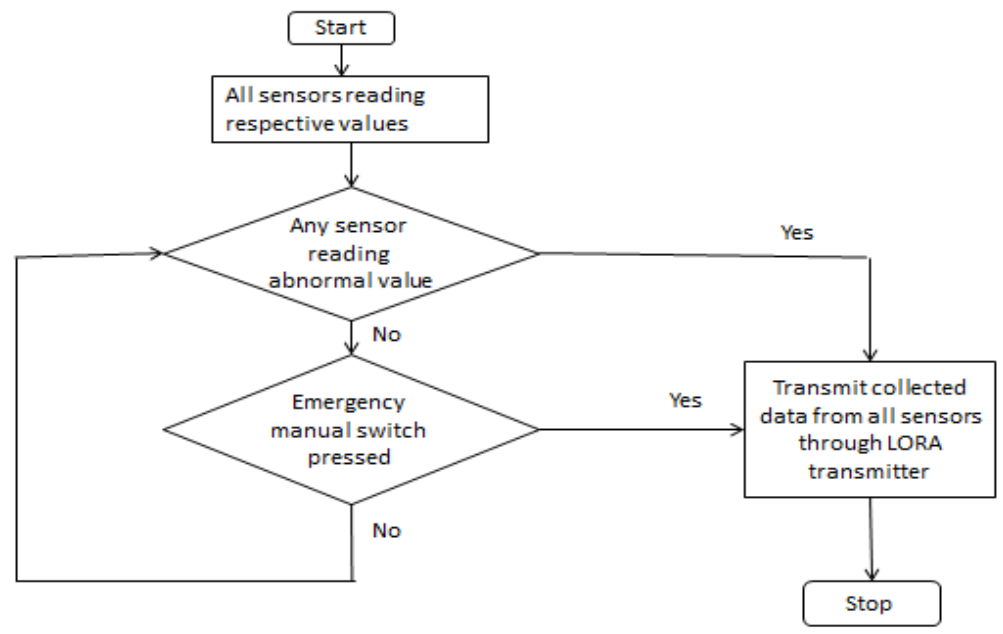

Figure-15: Flowchart Representation of Soldier's unit 
Journal of Ubiquitous Computing and Communication Technologies (UCCT) (2020)

Vol.02/ No.03

Pages: $153-177$

https://www.irojournals.com/jucct/

DOI: https://doi.org/10.36548/jucct.2020.3.005

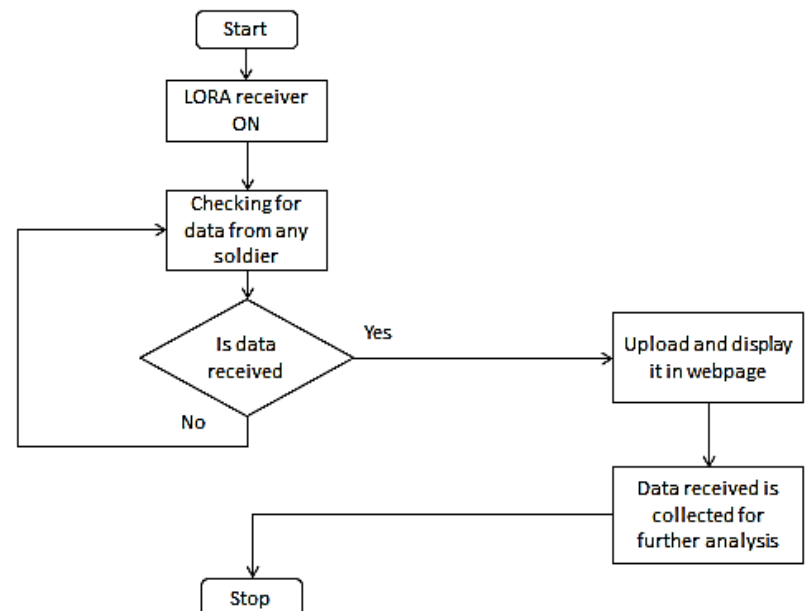

Figure-16: Flowchart Representation of Base station's unit

\subsection{Transmitting Arena}

The temperature sensor, ECG sensor, blood pressure sensor, SpO2 sensor, GPS module and LoRa transmitter are all interfaced with Node MCU controller. The GPS module interfaced is to locate the person's location. There is also a manual switch interfaced with the controller. There is an additional device which is ADC connected with Node MCU since there is less number of analog inputs in the controller. If any abnormal readings are detected from the sensors or the manual switch is pressed, then the readings are read by the controller and the LoRa transmitter transmits the data of the sensors to the LoRa receiver. The data is transmitted in the form of a string to the receiver.

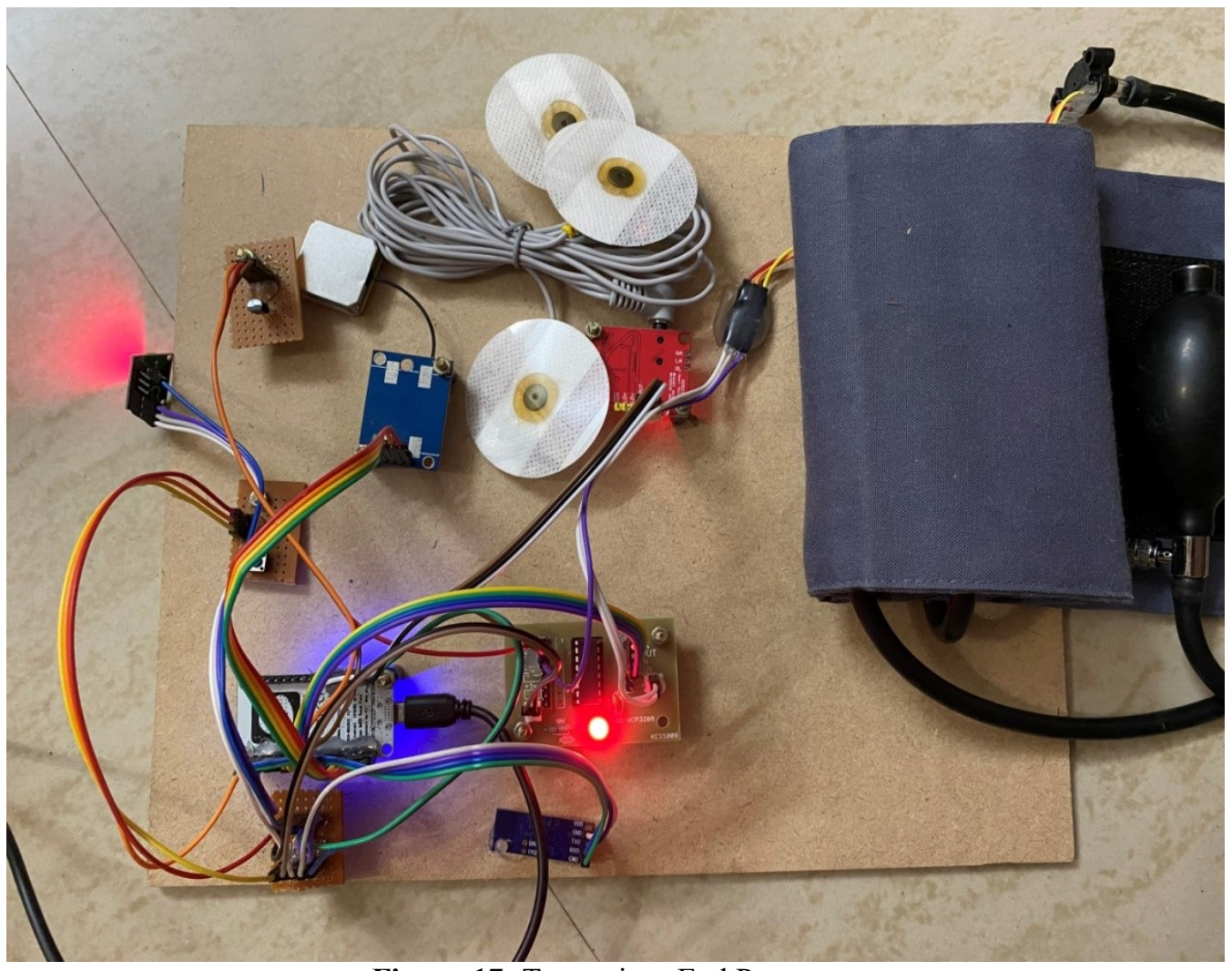

Figure-17: Transmitter End Prototype 
Journal of Ubiquitous Computing and Communication Technologies (UCCT) (2020)

Vol.02/ No.03

Pages: $153-177$

https://www.irojournals.com/jucct/

DOI: https://doi.org/10.36548/jucct.2020.3.005

\subsection{Receiving Arena}

The LoRa receiver collects the data from the LoRa transmitter and provides the data to the controller Node MCU. Then the Node MCU separates the string data as an individual sensor data, after that the Node MCU updates the information in a web server which is maintained through internet connection. Data transmission and uploading in the web server happens when any abnormal readings read by the controller or by pressing the manual switch. Node MCU is a Wi-Fi module used to connect the server and help in IOT application. The people at the base station monitor the health of the soldiers through web server.

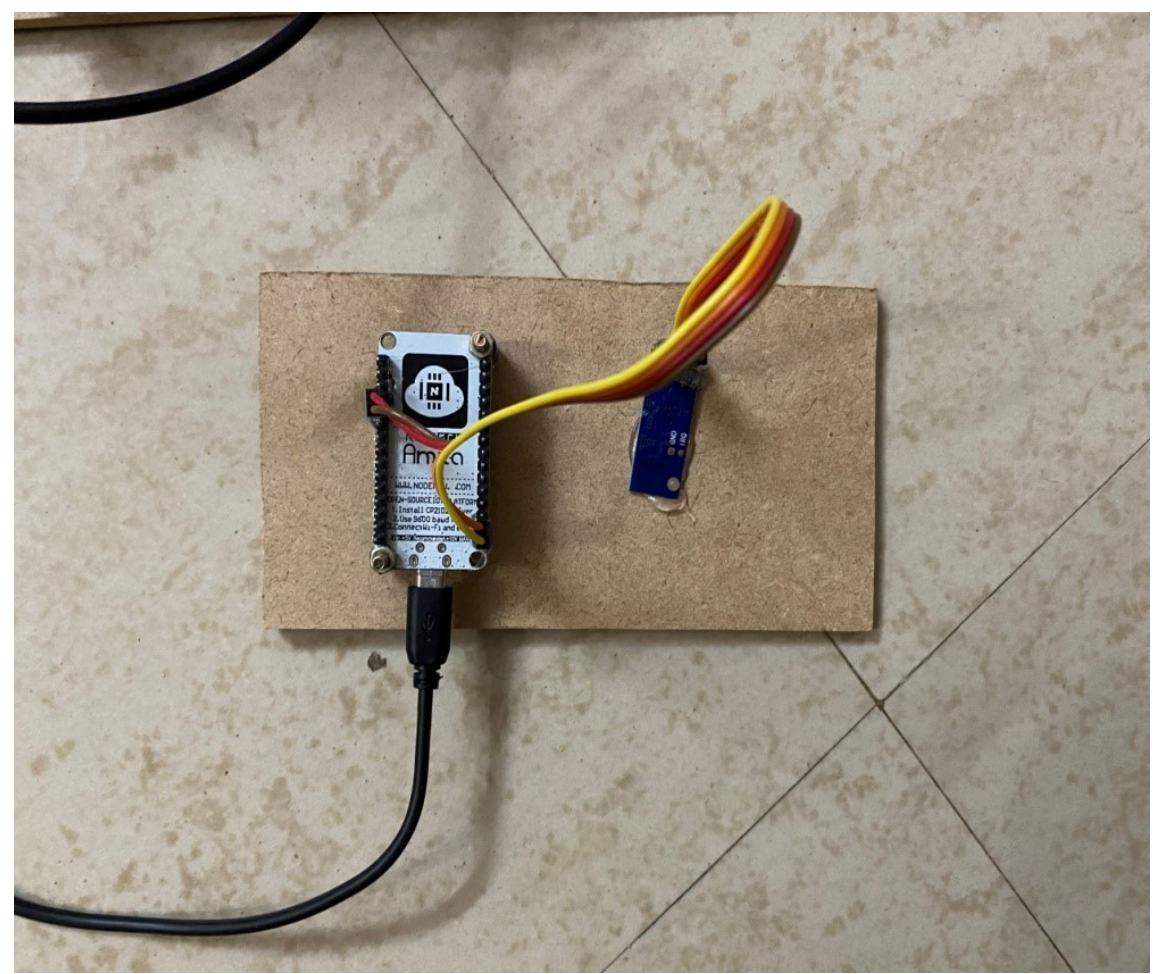

Figure-18: Receiver End Prototype

\subsection{Output}

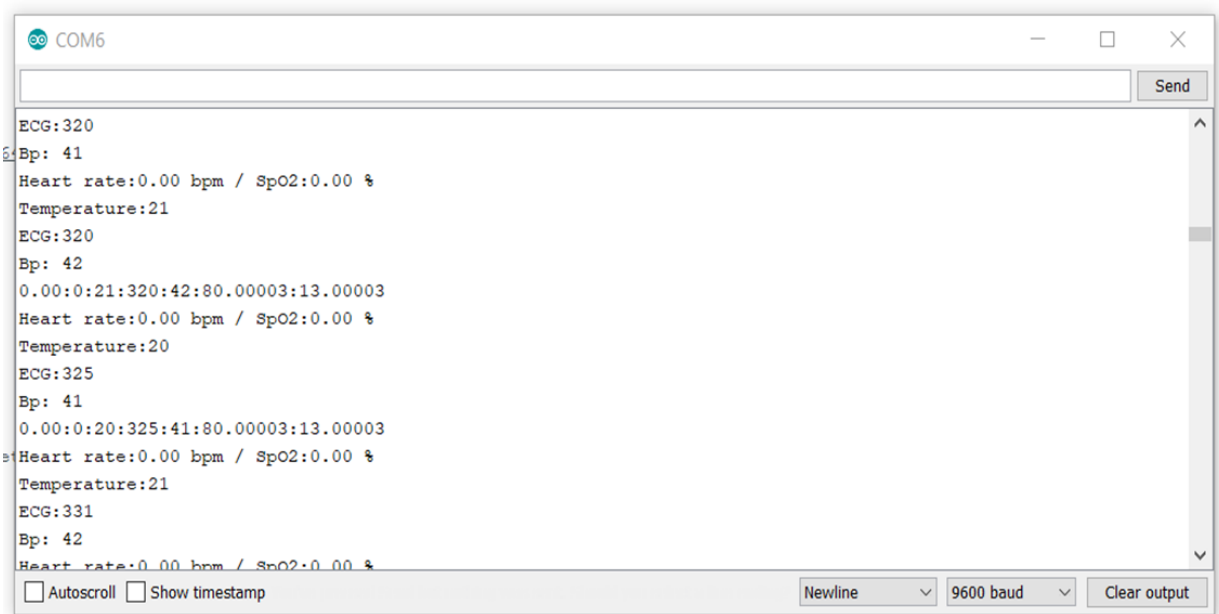

Figure-19: Transmitter side output 
Journal of Ubiquitous Computing and Communication Technologies (UCCT) (2020)

Vol.02/ No.03

Pages: $153-177$

https://www.irojournals.com/jucct/

DOI: https://doi.org/10.36548/jucct.2020.3.005

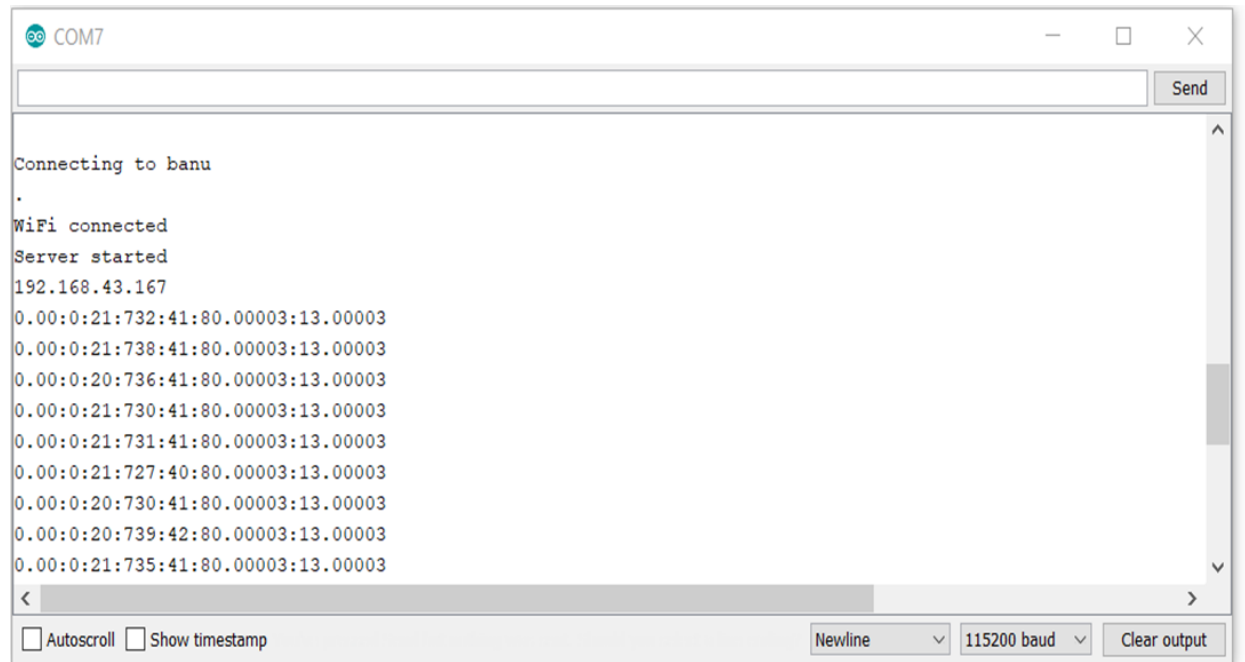

Figure-20: Receiver side output

\section{○) (1) 192.168 .43 .167 :}

\section{HEALTH MONITORING}

Location Details

\begin{tabular}{|c|c|}
\hline Temperature & 21 \\
\hline \hline ECG & 732 \\
\hline \hline Blood pressure & 42 \\
\hline \hline Beat & 0.00 \\
\hline spo2 & 0 \\
\hline \hline Latitude & 80.00003 \\
\hline \hline Longitutde & 13.00003 \\
\hline
\end{tabular}

Figure-21: Web page output

\subsection{Data Accumulation and Interpretation}

The Internet of Things (IoT) defines an evolving concept where the Internet is linked to a vast number of embedded devices (objects). Such linked devices interact with people and other items, and also provide cloud storage and cloud processing services with sensor data where the data is stored and evaluated for useful insights. This phenomenon is driven by cheap cloud storage resources and improved computer accessibility.

\subsubsection{MATLAB Analysis}

The MATLAB analysis is used to visualize and statistically analyze the sensor data in real time. Also we can aggregate the data on demand. We are using the power of MATLAB for sensing the IOT data. The collected sensor data is sent to the cloud privately. The analysis is done and we visualize the receiver data using MATLAB. 
Journal of Ubiquitous Computing and Communication Technologies (UCCT) (2020)

Vol.02/ No.03

Pages: $153-177$

https://www.irojournals.com/jucct/

DOI: https://doi.org/10.36548/jucct.2020.3.005

\subsubsection{Real time Output}

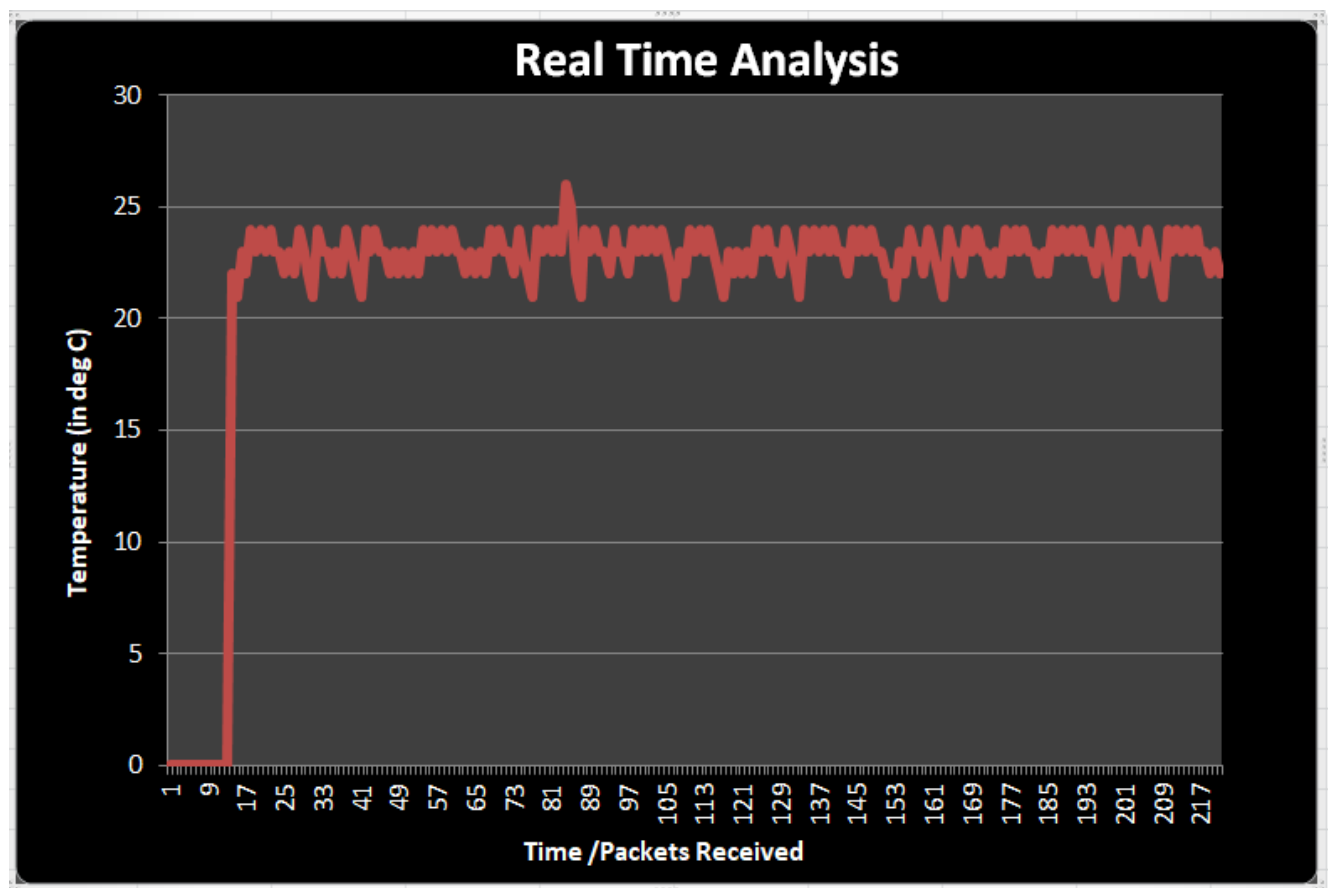

Figure-22: Real Time Analysis of Transmitted Data (Temperature sensor values)

\subsubsection{Alternative Way of Analysis}

Instead of using MATLAB for analysis, we can also use ThingSpeak, which is an IoT analytics network software that allows you to collect, display and interpret live data sources in the cloud. ThingSpeak makes instant analyzes of the data applied to ThingSpeak through computers. With the option to run MATLAB code in ThingSpeak, the data can be evaluated and interpreted on-line when it arrives. ThingSpeak is also used to test and prove IoT systems which involve analytics. Easily customize devices with common IoT protocols to submit data to ThingSpeak. Automatically run the IoT apps according to schedules or activities. Project and build IoT applications without deploying servers or designing web apps.

\subsubsection{MATLAB to Excel Representation:}

We can export our data used for analysis in MATLAB to Excel for innovative and easy visualization.

Charts help to condense or sum up vast quantities of data in a short, rectangular portion of your worksheet.

Charts will allow to see the patterns and developments inside the worksheet cells that may are blurred. Line, bar and region charts help you to deduce the trajectory and momentum of the data over time or as another measurement device.

Line charts may help to identify outliers or data objects that look out of position or irrelevant to other results. Outliers can be triggered by keyboard mistakes, malfunctions of devices, or merely meaningless, incomprehensible data that can be easily overlooked. Not only can outlying statistics run contrary to certain patterns or developments seen in the majority of the statistics, but they may bias or misrepresent percentages, amounts and other numerical analyses that you would like to do.

Charts will support the individual observing the Excel worksheets with data comprehend that is challenging to interpret or understand in terms or figures. Pie maps enable audiences easily understand figures, averages and 
Journal of Ubiquitous Computing and Communication Technologies (UCCT) (2020)

Vol.02/ No.03

Pages: $153-177$

https://www.irojournals.com/jucct/

DOI: https://doi.org/10.36548/jucct.2020.3.005

averages. Bar charts and column charts help to compare and rate data sets without ever knowing the raw numbers they contain.

The chart functions of Excel assist to rapidly visualize the data and acquire insights hidden deep within the columns and the rows of the raw worksheet.

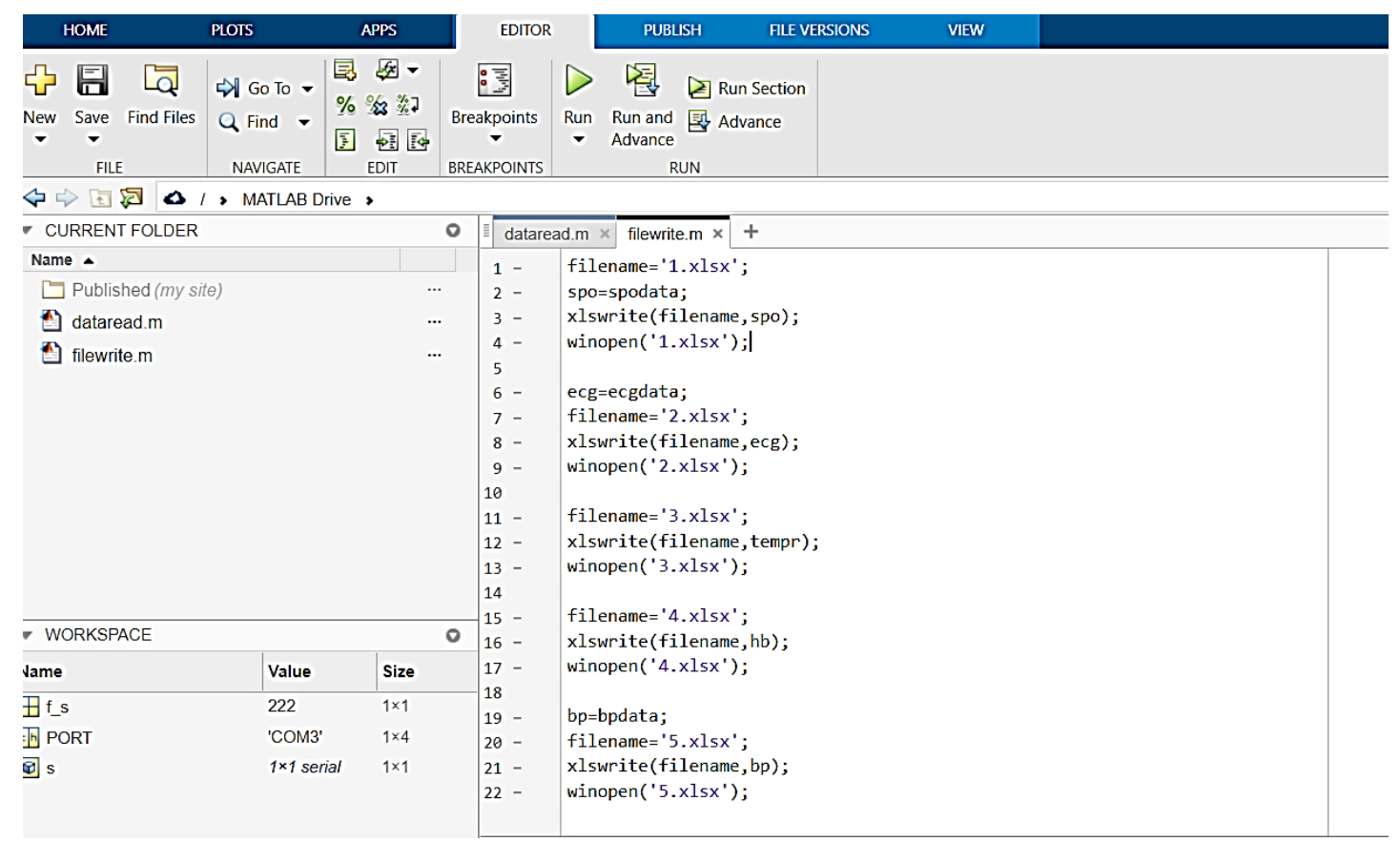

Figure-23: Code for exporting collected data from MATLAB to Excel

\subsection{Quality Indicators / Performance Metrics}

A metric is referred as the measurement of something. Utilize project metrics to track the progress. They are chosen on the basis of the project goals and essential success factors.

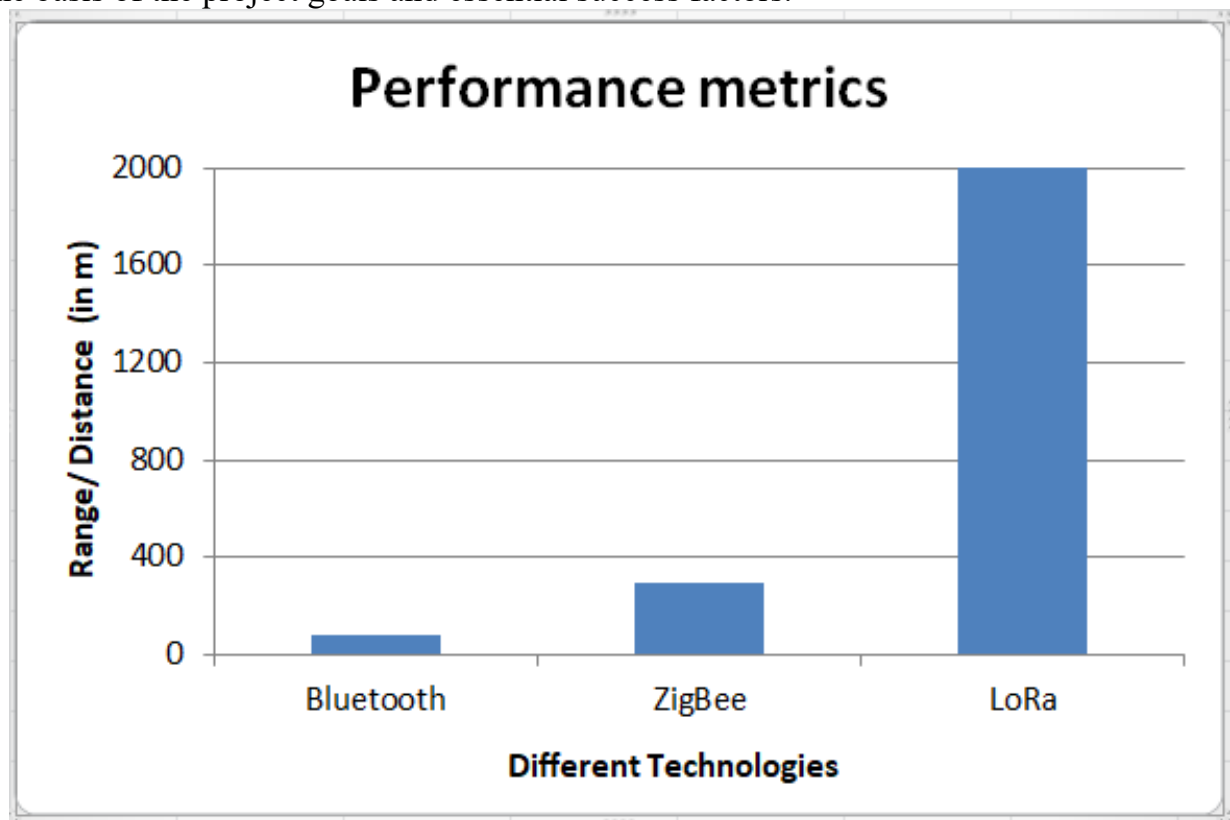

Chart-1: Comparison Chart - Coverage Distance 
Journal of Ubiquitous Computing and Communication Technologies (UCCT) (2020)

Vol.02/ No.03

Pages: $153-177$

https://www.irojournals.com/jucct/

DOI: https://doi.org/10.36548/jucct.2020.3.005

This shows the geographical coverage distance or the range of existing technologies (ZigBee, Bluetooth) and proposed technology (LoRa).

Packet Delivery Ratio:

Packet Delivery Ratio [27] is the proportion of the amount of data packets sent to the destination. This indicates the amount of data sent to destination.

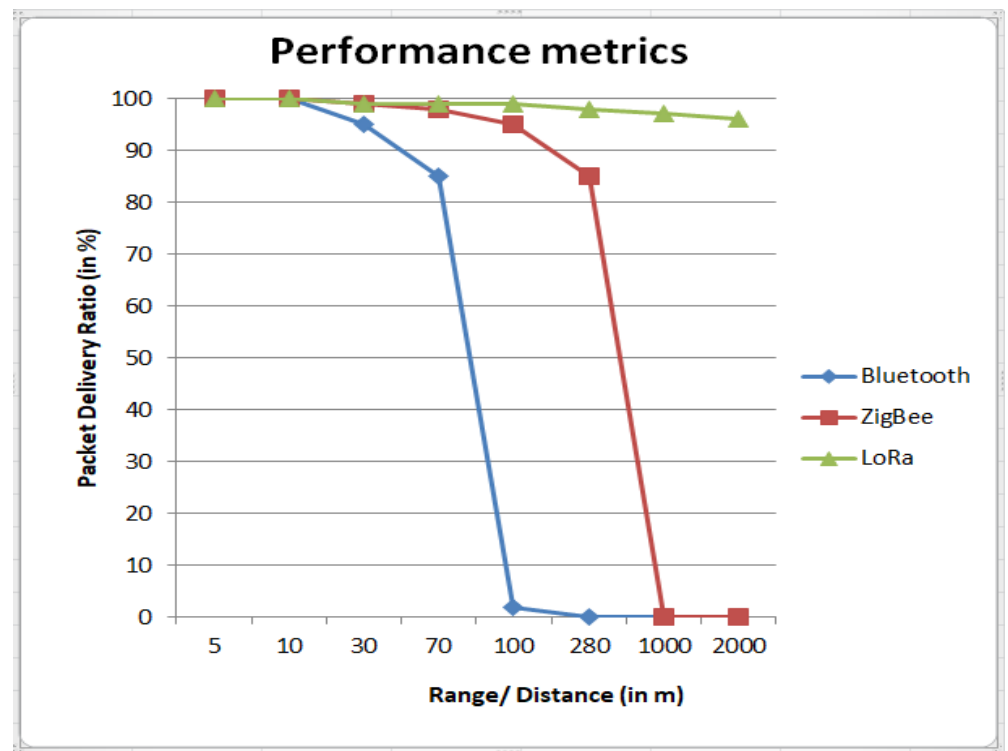

Chart-2: Comparison Chart - Packet delivery ratio

Packet Loss Ratio:

Packet loss occurs when 1 or more data packets are not reached their target through a computer network. The failure of the packets is usually triggered by interference in the network. Packet failure is calculated as a proportion of the packets lost to the total packets sent.

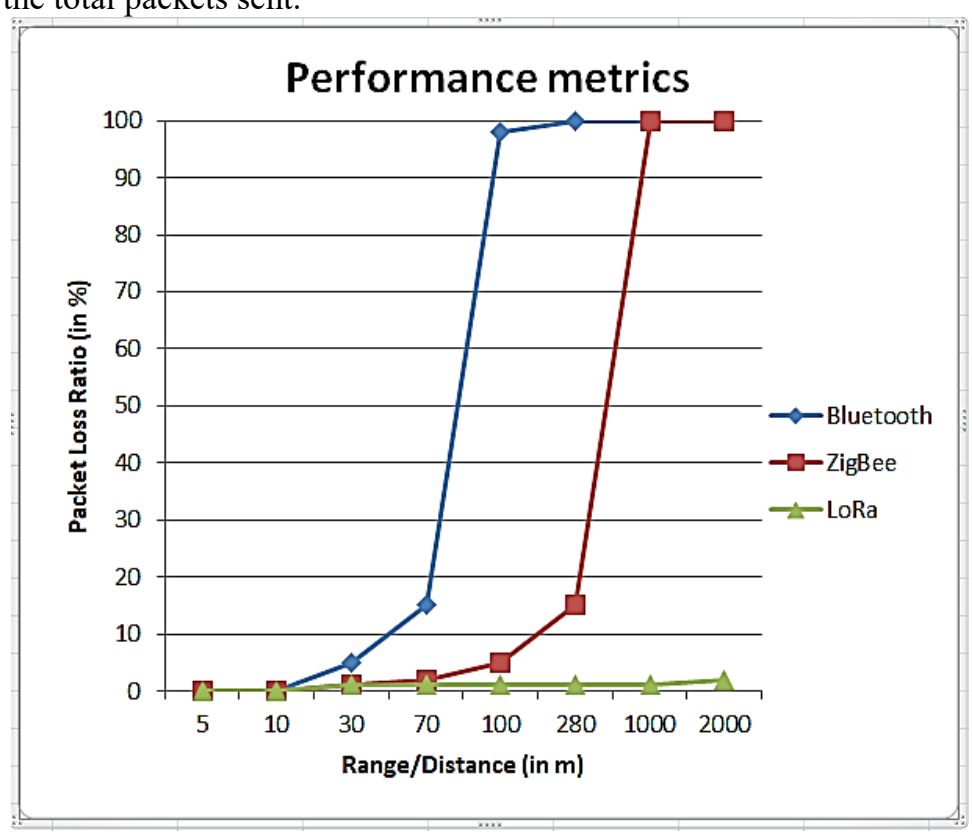

Chart-3: Comparison Chart - Packet loss ratio 
Journal of Ubiquitous Computing and Communication Technologies (UCCT) (2020)

Vol.02/ No.03

Pages: $153-177$

https://www.irojournals.com/jucct/

DOI: https://doi.org/10.36548/jucct.2020.3.005

Maximum Output Power:

Efficiency is the defined as the ratio of the total power output to the input power, which is expressed in percentage. Max output power is directly proportional to the output power.

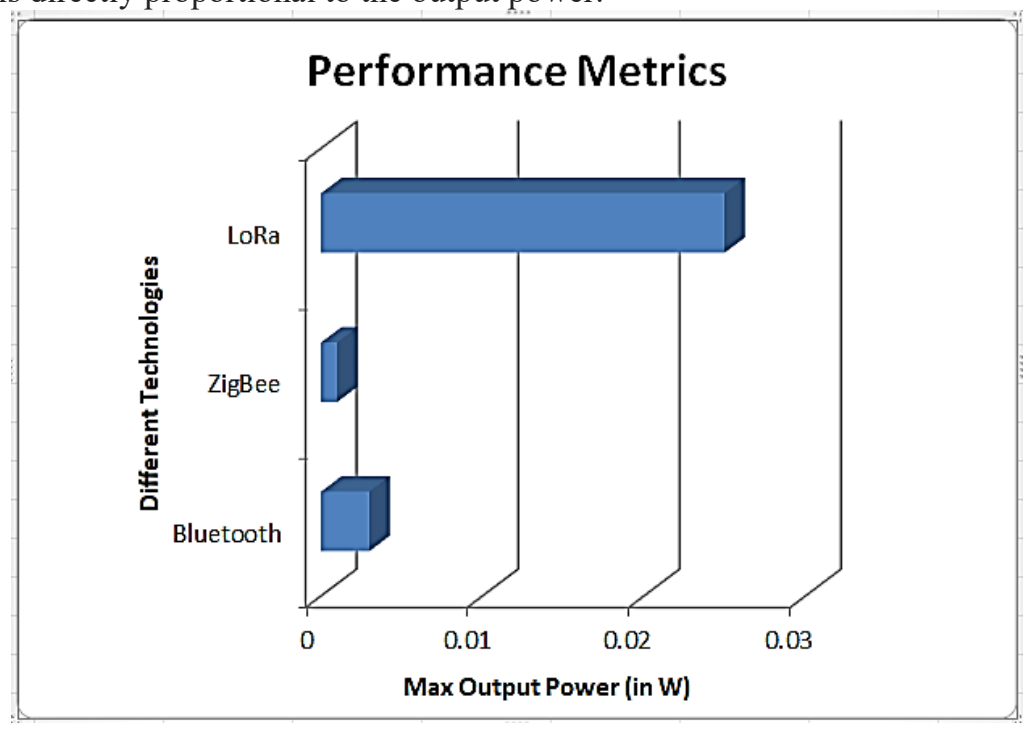

Chart-4: Comparison Chart - Maximum output power

Penetration Level:

There must be low penetration losses. Penetration level is indirectly proportional to the degradation factor which must be low. It directly affects the efficiency of the transmission.

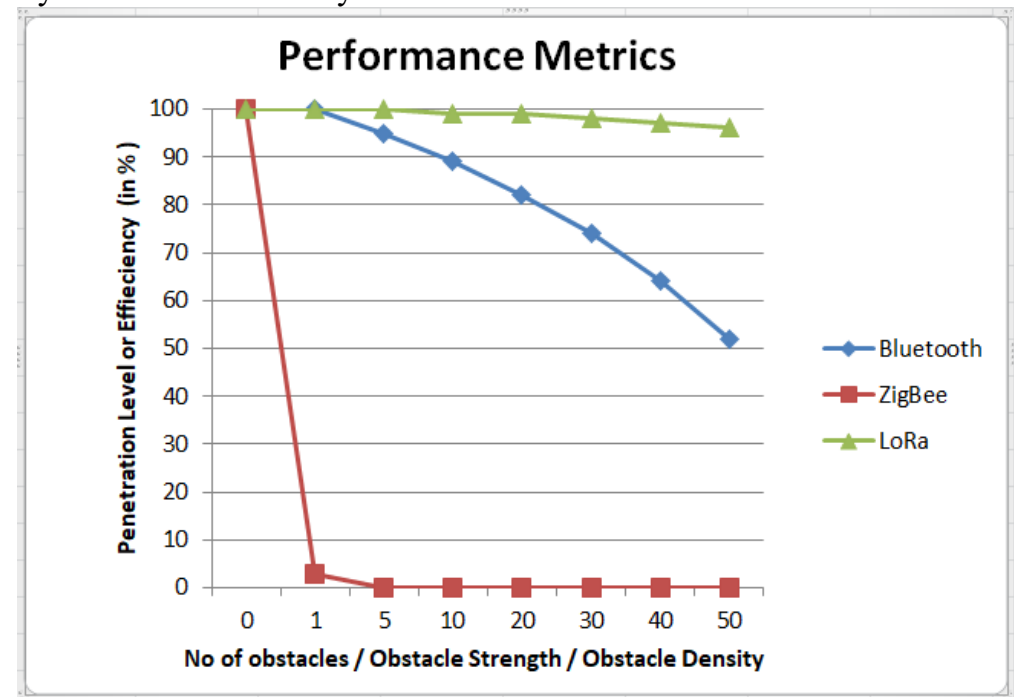

Chart-5: Comparison Chart - Efficiency vs Obstacle Density

\subsection{Results}

The results may involve an evaluation of the method used. In this paper, the results section would involve measuring the evaluating the success of the method.

Test cases are a collection of test items, preconditions, predicted outcomes and post circumstances, intended to validate conformity against a given criterion for a test scenario. We also planned and carried out a few test cases to check whether the concept meets the functional requirements. 
Journal of Ubiquitous Computing and Communication Technologies (UCCT) (2020)

Vol.02/ No.03

Pages: $153-177$

https://www.irojournals.com/jucct/

DOI: https://doi.org/10.36548/jucct.2020.3.005

Table-1: Test case at the soldiers' unit

\begin{tabular}{|c|c|c|c|}
\hline Test condition & Expected Output & Actual Output & Status \\
\hline $\begin{array}{c}\text { The soldier's vitals } \\
\text { exceed the normalized } \\
\text { values. }\end{array}$ & $\begin{array}{c}\text { Vitals to be transmitted } \\
\text { through LoRa to the receiving } \\
\text { end and checked in the serial } \\
\text { monitor. }\end{array}$ & $\begin{array}{c}\text { Vitals is transmitted through } \\
\text { LoRa to the receiving end and } \\
\text { checked in the serial monitor. }\end{array}$ & Success \\
\hline $\begin{array}{c}\text { A soldier presses the } \\
\text { alert switch. }\end{array}$ & $\begin{array}{c}\text { Vitals along with thelocation } \\
\text { of the soldier to be } \\
\text { transmitted through LoRa to } \\
\text { the receiver and checked in } \\
\text { the serial monitor. }\end{array}$ & $\begin{array}{c}\text { Vitals along with the location } \\
\text { of the soldier is transmitted } \\
\text { through LoRa to the receiver } \\
\text { and checked in the serial } \\
\text { monitor. }\end{array}$ & . \\
\hline
\end{tabular}

Table-2: Test case at the base station's unit

\begin{tabular}{|c|c|c|c|}
\hline Test condition & Expected Output & Actual Output & Status \\
\hline $\begin{array}{c}\text { Entering IP address in } \\
\text { the homepage of the web } \\
\text { page. }\end{array}$ & $\begin{array}{c}\text { Re-direction to monitoring } \\
\text { page of the web page. }\end{array}$ & $\begin{array}{c}\text { Redirection to monitoring page } \\
\text { of the web page. }\end{array}$ & Success \\
\hline $\begin{array}{c}\text { Abnormal values } \\
\text { detected from the soldier. }\end{array}$ & $\begin{array}{c}\text { Vitals and location } \\
\text { information to be updated on } \\
\text { analysis of real time data. }\end{array}$ & $\begin{array}{c}\text { Vitals and location information } \\
\text { are updated on the monitoring } \\
\text { web page and real time data is } \\
\text { analyzed. }\end{array}$ & Success \\
\hline $\begin{array}{c}\text { Alert switch pressed by } \\
\text { the soldier. }\end{array}$ & $\begin{array}{c}\text { Vitals and location } \\
\text { information to be updated on } \\
\text { the monitoring web page and } \\
\text { real time data to be analyzed. }\end{array}$ & $\begin{array}{c}\text { Vitals and location information } \\
\text { is updated on the monitoring } \\
\text { web page and real time data is } \\
\text { analyzed. }\end{array}$ & Success \\
\hline
\end{tabular}

\section{Conclusion}

A LoRa based monitoring system with IoT was implemented. By tracking the temperature, BP, SpO2, ECG we have introduced a protection device that also transmits the soldier's current position during emergency situations. This device helps military officers to be informed of the soldiers' situation at the bivouac. The rescue method is often rendered more effective by utilizing the geo-location to reduce the search region and to start checking early when the soldier's state of health becomes irregular. This can be a great help to the military personnel during combat and rescue efforts, because this system can be utilized with no network constraints. And this system gives security and defense to our soldiers.

The consequence of this plan is that the safety of the army soldiers should be constantly tracked, so that support can be provided to them. The safety of multiple military forces is tracked at the same time by utilizing this device. This program is particularly effective in distant areas where communication is challenging. The experimental results suggest that the system can provide reliable, real-time data. Ultimately, utilizing the WSN process, this program effectively developed a Wireless Device model for military operation.

This paper demonstrated this technology's strong utilitarianism which may therefore be seen as a substitute for current technologies, thus allowing smooth connectivity with equipment from multiple vendors which culminating in a cohesive and consistent way of diagnosing and tracking soldiers. 
Journal of Ubiquitous Computing and Communication Technologies (UCCT) (2020)

Vol.02/ No.03

Pages: $153-177$

https://www.irojournals.com/jucct/

DOI: https://doi.org/10.36548/jucct.2020.3.005

\section{Scope for Future Work}

In the future, the work may be expanded to a broad variety of uses such as tracking mines and employees and other dangerous situations and unsafe practices where it may be helpful in early identification of abnormalities and appropriate treatment can be taken. Gyroscope and Accelerometer may also be used together for the detection of human activity using machine learning.

This concept can be redirected to the manufacturing industrial sectors of body armor or combat vests. Therefore they will introduce the product themselves during their creation. This will turn out to be a growing and evolving one in the industry in the immediate future.

\section{Acknowledgement}

We were fortunate to acknowledge the help offered by professors of Easwari Engineering College, Chennai.

We express our heartfelt gratitude to Prof. M.Devaraju, Head of the Department of Electronics and Communication. We extend our sincere thanks to our mentor Prof. K.Rahimunnisa, without whose assistance and valuable advice our project wouldn't have been such a success. Also, we praise our faculty advisor Prof. K.Suriyakrishnaan for his consistent encouragement and support.

\section{Declaration of Conflicting Interests}

The authors declared no potential conflicts of interest with respect to the research, authorship, and/or publication of this article.

\section{Funding}

This research did not receive any specific grant from funding agencies in the public, commercial, or not-for-profit sectors.

\section{Dissemination of Results}

The results of our work have been shared in the form of a report to the academic unit of our University.

\section{Authorship Contribution Statement}

Mr. Shree Gowri Santhosh -- Conceptualization, Data curation, Formal analysis, Methodology, Validation, Visualization, Writing - original draft, Writing - review \& editing.

Mr. Vishal -- Conceptualization, Data curation, Formal analysis, Methodology, Validation, Visualization, Writing - original draft, Writing - review \& editing.

Mr. Vishak -- Conceptualization, Data curation, Formal analysis, Methodology, Validation, Visualization, Writing - original draft, Writing - review \& editing.

All the authors contributed to the drafting and approved the final version submitted for publication. All the authors agree to be accountable for all aspects of the published work.

\section{References}

[1]Fan Wu, Christoph Rüdiger, Jean-Michel Redouté, Jean-Michel Redouté (2018), "WE-Safe: A wearable IoT sensor node for safety applications via LoRa", IEEE 4th World Forum on Internet of Things (WF-IoT).

[2]Aswin Tresna Nugraha, Rianto Wibowo, Muhammad Suryanegara, Nur Hayati, "An IoT-LoRa system for tracking a patient with a mental disorder: Correlation between battery capacity and speed of movement",IEEE, 2018, 7th International Conference on Computer and Communication Engineering (ICCCE)

[3] Mahesh Sooriyabandara, Parag Kulkarni, Usman Raza, "Low power wide area network : An overview", IEEE Communications Surveys \& Tutorials ( Volume: 19 , Issue: 2 , Secondquarter 2017 )

[4]Hock Beng Lim, Di Ma, Bang Wang, Zbigniew Kalbarczyk, Ravishankar K. Iyer, Kenneth L. Watkin (2010) "A Soldier Health Monitoring System for Military Applications" International Conference on Body Sensor Networks, pp: (246-249).

[5]William Walker, A. L. Praveen Aroul, Dinesh Bhatia (2009) "Mobile Health Monitoring Systems" 31st Annual International Conference of the IEEE EMBS, Minneapolis, Minnesota, USA, pp: (5199-5202). 
Journal of Ubiquitous Computing and Communication Technologies (UCCT) (2020)

Vol.02/ No.03

Pages: $153-177$

https://www.irojournals.com/jucct/

DOI: https://doi.org/10.36548/jucct.2020.3.005

[6]M. Pranav Sailesh, C. Vimal Kumar, B. Cecil, B. M. Mangal Deep, P. Sivraj (2014) "Smart Soldier Assistance using WSN" International Conference on Embedded Systems - (ICES 2014), IEEE, pp: (244-249).

[7]P.S. Kurhe, S.S. Agrawal (2013) "Real Time Tracking and Health Monitoring System of Remote Soldier Using ARM 7", International Journal of Engineering Trends and Technology, 4(3), pp: (311-315).

[8]Shruti Nikam, Supriya Patil, Prajkta Powar, V. S. Bendre (2013) "GPS Based Soldier Tracking and Health Indication System" International Journal of Advanced Research in Electrical, Electronics and Instrumentation Engineering, 2(3), pp: (1082-1088).

[9]Prof. Pravin Wararkar, Sawan Mahajan, Ashu Mahajan, Arijit Banerjee, Anchal Madankar, Ashish Sontakke (2013) "Soldier Tracking and Health Monitoring System" The International Journal of Computer Science \& Applications, 2(02), pp: (81-86).

[10]Govindaraj A., Dr. S. Sindhuja Banu (2013) "GPS Based Soldier Tracking and Health Indication System with Environmental Analysis", International Journal of Enhanced Research in Science Technology \& Engineering, 2(12), pp: (46-52).

[11]Palve Pramod, "GPS Based Advanced Soldier Tracking With Emergency Messages \& Communication System” (2014) International Journal of Advance Research in Computer Science and Management Studies, 2(6), pp: (25-32).

[12]Mr. Rajdeep Limbu, Prof. V. V. Kale (2014) "GPS Based Soldier Tracking and Health Monitoring System" International Journal for Technological Research in Engineering, 1(12), pp: (1485-1488).

[13]Rubina.A.Shaikh (2012) "Real Time Health Monitoring System of Remote Patient Using Arm7" International Journal of Instrumentation, Control and Automation, 1(3-4), pp: (102-105).

[14]Dr. S. S. Riaz Ahamed (2009) "The Role of ZigBee Technology in Future Data Communication System" Journal of Theoretical and Applied Information Technology, 5(2), pp: (129-135).

[15]Nisha Ashok Somani, Yash Patel (2012) "ZigBee: A Low Power Wireless Technology for Industrial Applications" International Journal of Control Theory and Computer Modeling, 2(3), pp: (27-33).

[16]P. Rohitha, P. Ranjeet Kumar, Prof. N. Adinarayana, Prof. T. Venkat Narayana Rao (2012) "Wireless Networking through ZigBee Technology" International Journal of Advanced Research in Computer Science and Software Engineering, 2(7), pp: (49-54).

[17]Dineshkumar Jaiswar, Sanjna S. Repal (2015) "Real Time Tracking and Health Monitoring of Soldiers using ZigBee Technology: a Survey" International Journal of Innovative Research in Science, Engineering and Technology, 4(7).

[18]Shruti Nikam, Supriya Patil, Prajkta Powar, V.S.Bendre (2013) "GPS based Soldier Tracking and Health Indication System" International Journal of Advanced Research in Electrical, Electronics and Instrumentation Engineering, 2(3).

[19]Akshita V. Armarkar, Deepika J. Punekar, Mrunali V. Kapse, Sweta Kumari, Jayshree A. Shelke (2017) "Soldier Health and Position Tracking System" IJESC, 7(3).

[20]R. Archana, S. Indira (2013) "Soldier Monitoring and Health Indication System" (IJSR) International Journal of Science and Research.

[21]T. Yang, D. Mu, W.Hu, H. Zhang, "Energy-efficient border intrusion detection using wireless sensors network", EURASIP Journal on Wireless Communications and Networking, vol. 2014, no. 1, pp. 1-12, 2014. [Online]. Available: http://dx.doi.org/10.1186/1687-1499-2014-46

[22]P. Rothenpieler, D. Kruger, D. Pfisterer, S. Fischer, D. Dudek, C. Haas, A. Kuntz, and M. Zitterbart, "Flegsens - secure area monitoring using wireless sensor networks", in International Conference on Sensor Net- works, Information, and Ubiquitous Computing, 2009.

[23]Kim B., Kim Y., Lee I., ET AL.: "Design and implementation of a ubiquitous ECG monitoring system using SIP and the ZigBee networks". Proc. of the Future Generation Communication and Networking (FGCN 2007), Jeju, Korea, 6-8 December 2007, pp. 599-604

[24]Fariborz H., Moghawemi M., Mehrkanoon S.: "The design of an intelligent wireless sensor network for ubiquitous healthcare". Proc. of the Int. Conf. on Intelligent and Advanced System, Kualalumpur, Malaysia, 25-28 November 2007, pp. 414-417

[25]Sia H.-Y.H., Wang L.-H., Lin F.-C., ET AL.: "Design and implementation of a wireless ECG acquisition and communication system with health care services". Proc. of the Int. Symp. on Bioelectronics and Bioinformatics, Suzhou, 3-5 November 2011, pp. 25-28

[26]Yu B., Xu L., Li Y.: "Bluetooth low energy (BLE) based mobile electrocardiogram monitoring system". Proc. of the IEEE Int. Conf. on Information and Automation Shenyang, China, June 2012, pp. 763-767 
Journal of Ubiquitous Computing and Communication Technologies (UCCT) (2020)

Vol.02/ No.03

Pages: $153-177$

https://www.irojournals.com/jucct/

DOI: https://doi.org/10.36548/jucct.2020.3.005

[27]K. Suriyakrishnaan, D. Sridharan: "Reliable Packet Delivery in Wireless Body Area Networks Using TCDMA Algorithm for e-Health Monitoring system". Wireless Personal Communications--An International Journal, September 2018

\section{Abbreviations}

The following abbreviations are used in this manuscript.

\begin{tabular}{|c|c|}
\hline $\mathrm{ADC}$ & Analog to Digital Converter \\
\hline BP & Blood Pressure \\
\hline BSN & Body Sensor Network \\
\hline CSS & Chirp Spread Spectrum \\
\hline ECG & Electrocardiogram \\
\hline EDA & Electro-Dermal Activity \\
\hline EEPROM & Electrically Erasable Programmable Read Only Memory \\
\hline FEC & Further Error Correction \\
\hline FORTRAN & Formula Translation \\
\hline FSK & Frequency Shift Keying \\
\hline GFSK & Gaussian Frequency Shift Keying \\
\hline GPS & Global Positioning System \\
\hline GSM & Global System for Mobile Communication \\
\hline GUI & Graphical User Interface \\
\hline IDE & Integrated Development Environment \\
\hline IEEE & Institute of Electrical and Electronics Engineers \\
\hline IET & Institute of Engineering and Technology \\
\hline IETE & Institution of Electronics and Telecommunication Engineers \\
\hline IoT & Internet of Things \\
\hline ISM & Industrial, Scientific and Medical \\
\hline ISO & International Standard Organization \\
\hline ISTE & Indian Society of Technical Education \\
\hline LED & Light Emitting Diode \\
\hline LoRa & Long Range \\
\hline LoRaWAN & Long Range Wide Area Network \\
\hline LPWAN & Low Power Wide-Area Network \\
\hline MAC & Media Access Control \\
\hline MATLAB & Matrix Laboratory \\
\hline MCU & Micro Controller Unit \\
\hline NB-IoT & Narrow Band -Internet of Things \\
\hline $\mathrm{PC}$ & Personal Computer \\
\hline PHY & Physical Layer \\
\hline RF & Radio Frequency \\
\hline SAR & Standard Approximation Register \\
\hline SNR & Signal to Noise Ratio \\
\hline SPI & Serial Peripheral Interface \\
\hline $\mathrm{SpO} 2$ & Saturation of Peripheral Oxygen \\
\hline TTL & Transistor-Transistor Logic \\
\hline WBASN & Wireless Body Area Sensor Network \\
\hline WC & Wireless Communication \\
\hline Wi-Fi & Wireless Fidelity \\
\hline WSN & Wireless Sensor Network \\
\hline
\end{tabular}


Journal of Ubiquitous Computing and Communication Technologies (UCCT) (2020)

Vol.02/ No.03

Pages: $153-177$

https://www.irojournals.com/jucct/

DOI: https://doi.org/10.36548/jucct.2020.3.005

\section{Author's Profiles}

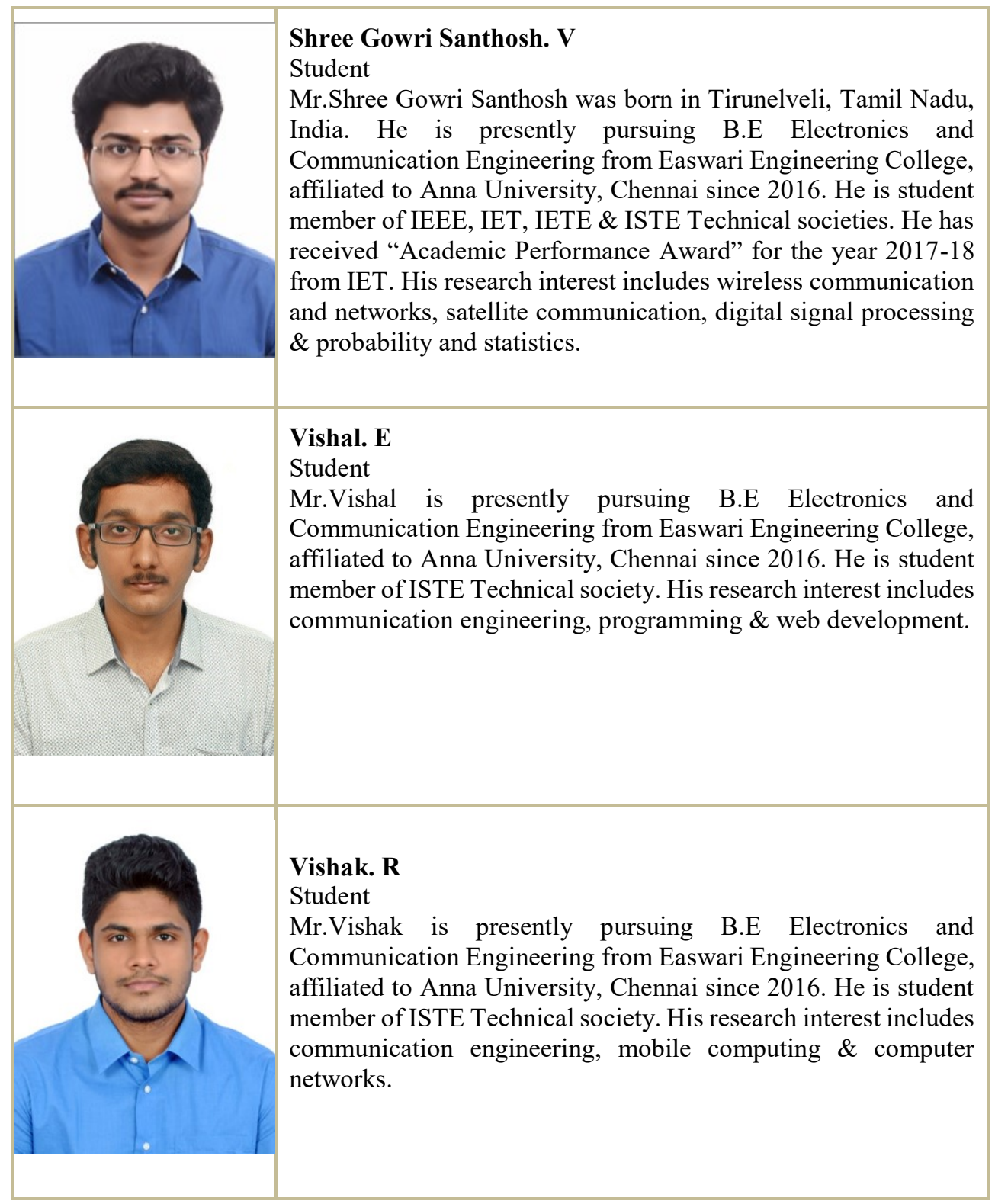

